\title{
Differential Proteomic Analysis of Human Placenta-Derived Mesenchymal Stem Cells Cultured on Normal Tissue Culture Surface and Hyaluronan-Coated Surface
}

\author{
Tzyy Yue Wong, ${ }^{1}$ Ying-Hui Chen, ${ }^{1}$ Szu-Heng Liu, ${ }^{1}$ Mairim Alexandra Solis, ${ }^{1}$ \\ Chen-Hsiang Yu, ${ }^{2}$ Chiung-Hsin Chang, ${ }^{2}$ and Lynn L. H. Huang ${ }^{1,3,4,5,6}$ \\ ${ }^{1}$ Institute of Biotechnology, College of Bioscience and Biotechnology, National Cheng Kung University, Tainan 701, Taiwan \\ ${ }^{2}$ Department of Obstetrics and Gynecology, National Cheng Kung University, Tainan 701, Taiwan \\ ${ }^{3}$ Department of Biotechnology and Bioindustry Sciences, National Cheng Kung University, Tainan 701, Taiwan \\ ${ }^{4}$ Institute of Clinical Medicine, College of Medicine, National Cheng Kung University, Tainan 701, Taiwan \\ ${ }^{5}$ Research Center of Excellence in Regenerative Medicine, National Cheng Kung University, Tainan 701, Taiwan \\ ${ }^{6}$ Advanced Optoelectronic Technology Center, National Cheng Kung University, Tainan 701, Taiwan
}

Correspondence should be addressed to Lynn L. H. Huang; lynn@mail.ncku.edu.tw

Received 16 May 2015; Revised 7 September 2015; Accepted 7 October 2015

Academic Editor: Andrzej Lange

Copyright (C) 2016 Tzyy Yue Wong et al. This is an open access article distributed under the Creative Commons Attribution License, which permits unrestricted use, distribution, and reproduction in any medium, provided the original work is properly cited.

\begin{abstract}
Our previous results showed that hyaluronan (HA) preserved human placenta-derived mesenchymal stem cells (PDMSC) in a slow cell cycling mode similar to quiescence, the pristine state of stem cells in vivo, and HA was found to prevent murine adiposederived mesenchymal stem cells from senescence. Here, stable isotope labeling by amino acid in cell culture (SILAC) proteomic profiling was used to evaluate the effects of HA on aging phenomenon in stem cells, comparing (1) old and young passage PDMSC cultured on normal tissue culture surface (TCS); (2) old passage on HA-coated surface (CHA) compared to TCS; (3) old and young passage on CHA. The results indicated that senescence-associated protein transgelin (TAGLN) was upregulated in old TCS. Protein CYR61, reportedly senescence-related, was downregulated in old CHA compared to old TCS. The SIRT1-interacting Nicotinamide phosphoribosyltransferase (NAMPT) increased by 2.23-fold in old CHA compared to old TCS, and is 0.48 -fold lower in old TCS compared to young TCS. Results also indicated that components of endoplasmic reticulum associated degradation (ERAD) pathway were upregulated in old CHA compared to old TCS cells, potentially for overcoming stress to maintain cell function and suppress senescence. Our data points to pathways that may be targeted by HA to maintain stem cells youth.
\end{abstract}

\section{Introduction}

Senescence is when cells reach an irreversible growth arrest [1] and is known to play roles in various biological processes such as development, apoptosis, and aging [2]. It was reviewed that mitotic cells, cells undergoing proliferation, are prone to senescence [3]. Mitotic cells include stem cells, epithelial, vascular, and fibroblastic cells. The model for cellular senescence first originated from Hayflick and Moorhead, who reported in 1961 that normal human diploid cells had limited replicative lifespan [4]. Since then, senescence is believed to play a role in two potential circumstances, namely, (1) to prevent tumor growth and (2) as a normal way towards aging. The trigger of cellular aging includes many factors, such as oxidative stress [5], genomic instability [6], altered niche microenvironment [6], altered mitochondrial function [7, 8], altered epigenetic regulations [9], and stem cells exhaustion [9]. Previous study showed that genome stability such as maintained telomere length extended cell population doubling and reduced cellular aging in normal retinal pigment epithelial cells and foreskin fibroblasts [10]. Thus, the link between limited replicative senescence and actual aging phenomenon had been established.

The known aging mechanisms include telomere shortening [11], reactive oxygen species (ROS) accumulation, accumulated DNA damage-induced cell cycle regulation factors 
p53, p16, and p21 $[3,6]$, and altered cytoplasmic metabolism [12], all potentially leading to aging. The aging of stem cells leading to stem cell population decline had been suggested to occur in the human disease known as Hutchinson Gilford Progeria Syndrome [13]. The mesenchymal stem cells (MSC) from aged Sprague-Dawley rats were found to have compromised MSC function compared to that from young Sprague-Dawley rats [14]. The MSC are maintained in vivo as multipotent cells, capable of adipogenesis, osteogenesis, and chondrogenesis differentiation. Although it is well-known that stem cells are preserved in a pristine or youthful state compared to somatic cells in vivo, the mechanism involved is not fully understood. As a result, MSC are presented as a good model for studying the aging phenomenon.

The goal was to study aging phenomenon using stable isotope labeling by amino acid in cell culture (SILAC), a nonradioactive labeling method to label human placenta-derived MSC (PDMSC). This study aimed to confirm the previous results observed with hyaluronan (HA) presence. HA is a major component of extracellular matrix (ECM) that belongs to the glycosaminoglycan (GAG) family. It was observed that HA played a role in maintaining PDMSC in slowcell cycling mode similar to stem cell quiescence [15]. HA induced multidrug resistance in PDMSC via CD44-PI3KAkt pathway [16]. HA was found to prevent murine adiposederived stromal cells from senescence [17]. PDMSC of older passage was compared to younger passage. It was found that PDMSC underwent replicative senescence after long-term in vitro expansion, in particular, the upregulation of proaging proteins and structural proteins. Molecules pertaining to normal cell function maintenance such as the endoplasmic reticulum-associated degradation (ERAD) pathway during stress and the COP9 signalosome-specific phosphorylation for p53 degradation were upregulated under HA presence compared to without HA, suggesting that the PDMSC under HA culture condition intended to suppress the stress of aging.

\section{Materials and Methods}

2.1. Cell Isolation. Full-term human placentas were obtained from mothers at the National Cheng Kung University Hospital with informed consent. Procedure of the human placenta handling and cell isolation was approved by the Institutional Review Board. PDMSC were isolated based on previous method [15]. In brief, the chorionic villi layer was harvested and rinsed in Hanks' Balanced Salt Solution (Sigma, St. Louis, MO, USA). The tissues were cut into tiny pieces and digested by $347 \mathrm{U} / \mathrm{mL}$ Collagenase Type 2 (Worthington Biochemical Corporation) at $37^{\circ} \mathrm{C}$ for $40 \mathrm{~min}$. The digested tissues went through filters from 500 and 104 to $37 \mu \mathrm{m}$. Percoll (Percoll; GE Healthcare, Uppsala, Sweden) was used for density gradient centrifugation to isolate mononuclear cells. The isolated cells were seeded at $3 \times 10^{4}$ per $\mathrm{cm}^{2}$ in Dulbecco's modified Eagle's mediumlow glucose, with $10 \%$ fetal bovine serum from Gibco BRL, Life Technologies, Grand Island, NY, USA, at $37^{\circ} \mathrm{C}$ with $5 \%$ $\mathrm{CO}_{2}$. Cells were cultured for 10-14 days until they reached a confluence of $70-80 \%$ and then passaged. The cells cultured on $30 \mu \mathrm{g} / \mathrm{cm}^{2}$ HA-coated plates were termed CHA; those cultured on polystyrene tissue-culture surface were termed TCS.

2.2. Differentiation Potential Analysis. For adipogenic differentiation, induction medium contained final concentration of $1 \mu \mathrm{M}$ dimethyl sulfoxide (DMSO; Sigma, St. Louis, MO, USA), $0.2 \mathrm{mM}$ indomethacin (Sigma, St. Louis, MO, USA), $0.5 \mathrm{mM}$ 3-Isobutyl-1-methylxanthine (IBMX; Sigma, St. Louis, MO, USA), $10 \mu \mathrm{M}$ insulin, and $10 \%$ fetal bovine serum (FBS; GibcoBRL, Grand Island, NY, USA) in Dulbecco's modified Eagle's medium high glucose medium (DMEM; Gibco BRL, Grand Island, NY, USA). Cells were seeded at density $1 \times 10^{4}$ per $\mathrm{cm}^{2}$ until $100 \%$ confluence was reached, and medium was changed to induction medium for 4 weeks. Induction medium was changed every 72 hours. Oil Red O (Sigma, St. Louis, MO, USA) was used to stain oil droplets. In brief, cells were fixed in $4 \%$ paraformaldehyde, washed with $1 \mathrm{x}$ phosphate buffer saline (PBS), rinsed in $60 \%$ isopropanol for three minutes, and stained in Oil Red O for 1 hour. After that, cells were washed using $60 \%$ isopropanol once, then rinsed in double-distilled water, and rinsed in $0.05 \%(\mathrm{w} / \mathrm{v})$ sodium carbonate solution (Riedel-de Haën, Sigma, St. Louis, MO, USA) for two minutes. Finally, cells were counterstained with hematoxylin for one minute, washed with water, and analyzed under microscope. For chondrogenic differentiation, induction medium contained final concentration of $6.25 \mu \mathrm{g} / \mathrm{mL}$ insulin, $50 \mathrm{nM}$ ascorbic acid (JT Baker), and $10 \mathrm{ng} / \mathrm{mL}$ tumor growth factor-betal (TGF- $\beta 1$; CellGS, St. Louis, MO, USA) in DMEM high glucose medium without FBS. Cells were seeded at density $1 \times$ $10^{4}$ per $\mathrm{cm}^{2}$ until $100 \%$ confluence was reached, and medium was changed to induction medium for 4 weeks. Induction medium was changed every 72 hours. Accumulation of glycosaminoglycan was analyzed by staining with Alcian blue (Sigma, St. Louis, MO, USA). Briefly, cells were fixed in 4\% paraformaldehyde, washed with PBS, and incubated in $1 \mathrm{~N}$ hydrogen chloride (HCl; Sigma, St. Louis, MO, USA) solution for five minutes. Next, cells were stained with 3\% Alcian blue solution in $0.1 \mathrm{~N} \mathrm{HCl}$ for 30 minutes. Finally, cells were washed with water and analyzed under microscope. Osteogenesis differentiation assay was performed using the induction medium supplemented with $10 \mu \mathrm{M}$ DMSO, $10 \mathrm{nM}$ ascorbic acid, $10 \mathrm{mM}$ 2-glycerophosphate (Sigma, St. Louis, MO, USA), and 10\% FBS in DMEM high glucose medium. Seeding cell density was $1 \times 10^{4}$ per $\mathrm{cm}^{2}$, and experiment was performed upon reaching $100 \%$ confluence. Calcification was visualized after staining with Alizarin Red S (Sigma, St. Louis, MO, USA). Cells were fixed in $4 \%$ paraformaldehyde, washed with PBS, and stained in Alizarin Red S solution for 20 minutes. Finally, cells were washed with water three times and analyzed microscopically.

2.3. Cumulative Population Doubling. To determine cumulative population doubling, cells were seeded at $0.7 \times 10^{4}$ per $\mathrm{cm}^{2}$ for normal tissue-culture surface without HA (TCS), and $2.5 \times 10^{4}$ per $\mathrm{cm}^{2}$ for HA-coated surface (CHA) on 24well plate. Cells were subcultured when $80 \%$ confluence was reached, and cell number was counted. Population doubling 
was calculated using the equation: Logarithm of (final total cell number/initial cell number seeded) to base two. Finally, cumulative population doubling was derived by taking the sum of each population doubling.

2.4. SILAC Cell Culture. The cells, PDMSC, were cultured in arginine and lysine minus DMEM-low glucose (Sigma, St. Louis, MO, USA), with 10\% dialyzed FBS (Thermo Fisher Scientific Incorporation, MA, USA) for 5-6 doublings, and tested for heavy-labeled incorporation efficiency before analysis of protein. The heavy amino acids ${ }^{13} \mathrm{C}_{6}$ L-Arginine$\mathrm{HCl}$ and ${ }^{13} \mathrm{C}_{6}$ L-lysine- $2 \mathrm{HCl}$ were supplemented at final concentration $0.1 \mathrm{mg} / \mathrm{mL}$ in DMEM-low glucose for heavy labeling, whereas $\mathrm{L}$-arginine- $\mathrm{HCl}$ and $\mathrm{L}$-lysine-2 $\mathrm{HCl}$ were supplemented at final concentration $0.1 \mathrm{mg} / \mathrm{mL}$ in DMEMlow glucose for light labeling. All the amino acids for labeling were purchased from Thermo Fisher Scientific Incorporation, MA, USA. Incorporation of cells with either heavy or light amino acids commenced from passages two to five for young PDMSC, and from passages 14 to 17 for old PDMSC. The old TCS $\left(\mathrm{OTCS}^{\mathrm{H}}\right)$ and young $\mathrm{CHA}\left(\mathrm{YCHA}^{\mathrm{H}}\right)$ were heavylabeled; the young TCS (YTCS ${ }^{\mathrm{L}}$ ) and old CHA $\left(\mathrm{OCHA}^{\mathrm{L}}\right)$ were light-labeled.

2.5. Hyaluronan-Coated Surface Preparation. Hyaluronan $(\mathrm{Mw}=1470 \mathrm{kDa}$; Lifecore, MN, USA) was first dissolved in double-distilled water and then to working concentrations right before use. The hyaluronan was administered onto polystyrene surface and dried using hot plate for $30 \mathrm{~min}$. The final concentration of hyaluronan was $30 \mu \mathrm{g} / \mathrm{cm}^{2}$.

2.6. Sample Preparation. Method for sample collection was referred to previous [18] method with a few modifications. Reduction buffer containing $25 \mathrm{mM}$ ammonium bicarbonate (ABC; Sigma, St. Louis, MO, USA), $2 \mathrm{mM}$ dithiothreitol (DTT; JT Baker), and $8 \mathrm{M}$ urea (Sigma, St. Louis, MO, USA) with complete protease inhibitor mixture (Roche Applied Science) was used to lyse cells on ice. A scraper was used to collect lysates and transferred to a new microcentrifuge tube. The lysates were left on ice for $30 \mathrm{~min}$ and vortexed intermittently in every $5 \mathrm{~min}$. After that, lysates were centrifuged for $20 \mathrm{~min}$ at $18^{\circ} \mathrm{C}, 20,000 \mathrm{~g}$. Supernatant was collected in new microcentrifuge tube, quantified using Bradford assay. The collected protein lysates were checked for integrity by $8 \%$ sodium dodecyl sulfate-polyacrylamide gel electrophoresis (SDS-PAGE) before further analysis. Protein concentration was measured using Bradford assay (Thermo Fisher Scientific Incorporation, MA, USA), and absorbance was measured at $595 \mathrm{~nm}$. Protein of $10 \mu \mathrm{g}$ was added into $10 \mu \mathrm{L}$ of reduction buffer, kept at $37^{\circ} \mathrm{C}$ for $1 \mathrm{hr}$. Solution of $20 \mathrm{mM}$ iodoacetamide (Sigma, St. Louis, MO, USA) prepared in $25 \mathrm{mM}$ of ABC was added for sulphur-hydrogen groups alkylation, reacted at room temperature for $1 \mathrm{hr}$ in the dark. Then, $20 \mathrm{mM}$ DTT was used to quench the alkylation. The concentration of urea was brought down to less than $1 \mathrm{M}$ with the $25 \mathrm{mM} \mathrm{ABC}$. Lysates were digested in $0.1 \mu \mathrm{g} / \mu \mathrm{L}$ lysine-C (Wako Chemicals, Richmond, VA, USA) at $37^{\circ} \mathrm{C}$ for $2 \mathrm{hr}$. Followed by further $0.1 \mu \mathrm{g} / \mu \mathrm{L}$ trypsin (Promega, Madison, WI, USA) digestion at $30^{\circ} \mathrm{C}$ for $12 \mathrm{hr}$. The reaction was stopped by adding $1 \%$ of formic acid (Sigma, St. Louis, MO, USA). Each protein sample was loaded on $\mathrm{C}_{18}$ Ziptip (Millipore, Temecula, CA, USA) for purification. Finally, the mixture was desiccated using speed vacuum until dried before sending for LTQOrbitrap XL (Thermo Fisher Scientific Incorporation, MA, USA) LC-MS/MS at the Academia Sinica, Institute of Biological Chemistry. The protein lysates of $\mathrm{OTCS}^{\mathrm{H}}$ were mixed with $\mathrm{YTCS}^{\mathrm{L}}$, OCHA ${ }^{\mathrm{L}}$ mixed with $\mathrm{OTCS}^{\mathrm{H}}$, and $\mathrm{OCHA}^{\mathrm{L}}$ mixed with $\mathrm{YCHA}^{\mathrm{H}}$ in same cell number.

2.7. Incorporation Efficiency Analysis. Before sending experimental mixed samples for liquid chromatography-tandem mass spectrometry (LC-MS/MS) identification and quantitation, aliquots of the heavy-labeled protein lysates were first assessed for incorporation efficiency using LC-MS/MS for heavy amino acids-labeled peptides incorporation percentage. The parameters set for incorporation efficiency analysis were the same as in the mass spectrometry data analysis for the mixed experimental groups mentioned in the following section. The incorporation percentage was analyzed using DanteR (1.0.0.10 version) software in which parameters were set according to MaxQuant format. The incorporation percentage above $95 \%$ for heavy amino acids was required for further protein identification and quantitation.

2.8. Mass Spectrometry Data Analysis. Raw data obtained from LC-MS/MS was analyzed using MaxQuant (1.3.0.5 version, Max Planck Institute of Biochemistry), and proteins were identified based on the human FASTA file (downloaded in June 2013) from Uniprot. The raw data from LCMS/MS was uploaded to MaxQuant, and MS/MS spectra were further searched using Andromeda search engine. For parameters, the number of missed cleavages allowed was two. For MS/MS spectrum and sequence parameters, Fourier transform mass spectrum (FTMS), ion-trap mass spectrum (ITMS), and time-of-flight (TOF) were set to 20 p.p.m, $0.5 \mathrm{Da}$, and $0.1 \mathrm{Da}$, respectively, whereas for the top peaks per $100 \mathrm{Da}$, FTMS, ITMS, and TOF were set to 10 p.p.m, $6 \mathrm{Da}$, and $10 \mathrm{Da}$, respectively. The raw data was searched with fixed modification carbamidomethyl. For identification and quantification parameters, peptide false discovery rate (FDR), site FDR, maximal peptide posterior error probability (PEP), minimum peptides, minimal razor plus unique peptides, and minimal unique peptides were set at $0.01,0.01,1,1,1$, and zero, respectively. Finally, the protein FDR was set at $0.01 \%$. To be considered SILAC pair, the identified peptides had mass difference of $6 \mathrm{Da}$. From MaxQuant analysis, the protein identity, the heavy to light ratios, and peptide intensities were shown in columns in the result. Protein abundance was derived from the peptide intensity in logarithm to base of 10 and the normalized heavy- and light-labeled protein ratios in logarithm to base of two. The normalized ratios $\geqq 1.50$ were discussed in this study.

2.9. Functional Analysis. To analyze protein functions, UniProtKB/Swiss-Prot was used, in combination with STRING9.1. Proteins with significance analyzed from Perseus 
software (1.3.0.4, Max Planck Institute of Biochemistry) for normalized ratios were selected from the experimental groups and searched using UniProtKB/Swiss-Prot. Proteins that lack previous study as reference were confirmed using STRING9.1 for protein-protein networks.

2.10. Statistical Analysis. For statistical analysis, Student's $t$ test was used to calculate $P$ value. For proteomic analysis, the software Perseus was used to calculate significance $B$ for $P$ value. Proteins that deviate significantly from zero point (where heavy to light ratio equals zero) in the abundant proteins show the highest significance $B$ value with the lowest $P$ value where $P$ values below 0.05 were identified as significant.

\section{Results}

3.1. Hyaluronan Influenced PDMSC Proliferation. The PDMSC isolated from human placenta demonstrated adipogenic, chondrogenic, and osteogenic differentiation potential after a period of 4 -week induction (Figure 1(a)). The morphology for PDMSC cultured on TCS was fibroblastic at passage 5 and was more spread at passage 17 (Figure 1(b)). In contrary, PDMSC cultured on CHA formed aggregate (Figure 1(b)). Proliferative profile for PDMSC cultured on TCS varied significantly from CHA (Figure 1(c)). To further investigate hyaluronan effect on PDMSC, protein lysates were collected and integrity was determined using SDS gel for YTCS, YCHA, OTCS, and OCHA (Figure 2(a)). Figures 2(c)-2(f) show the incorporation percentage for heavy arginine and lysine which were above 95\% for OTCS and YCHA.

3.2. Different Patterns of Aging Phenomena with and without Hyaluronan. Result showed that a total of 965, 1038, and 916 proteins were identified in the groups $\mathrm{OTCS}^{\mathrm{H}}$ versus $\mathrm{YTCS}^{\mathrm{L}}, \mathrm{OCHA}^{\mathrm{L}}$ versus $\mathrm{OTCS}^{\mathrm{H}}$, and $\mathrm{OCHA}^{\mathrm{L}}$ versus $\mathrm{YCHA}^{\mathrm{H}}$, respectively (Figures 3(a)-3(c)). The protein distribution in the aging phenomenon for OTCS ${ }^{\mathrm{H}} \mathrm{YTCS}^{\mathrm{L}}$ differed from $\mathrm{OCHA}^{\mathrm{L}}: \mathrm{YCHA}^{\mathrm{H}}$ in that $\mathrm{OCHA}^{\mathrm{L}}: \mathrm{YCHA}^{\mathrm{H}}$ had $13.4 \%$ and $8.0 \%$ proteins for biosynthesis/degradation and epigenetics, respectively; $\mathrm{OTCS}^{\mathrm{H}}: \mathrm{YTCS}^{\mathrm{L}}$ had $3.8 \%$ and $1.3 \%$ proteins for biosynthesis/degradation and epigenetics, respectively (Figures 3(a) and 3(c)). Between $\mathrm{OCHA}^{\mathrm{L}}$ and $\mathrm{OTCS}^{\mathrm{H}}, 11$ out of $94(11.7 \%)$ were structural, and 29 out of $94(30.9 \%)$ were signal transduction proteins (Figures 3(a) and 3(b)). Interestingly, replication-related genes were not found to be modulated in the $\mathrm{OTCS}^{\mathrm{H}}$ :YTCS ${ }^{\mathrm{L}}$ (Figure 3(a)).

The OCHA ${ }^{\mathrm{L}}: \mathrm{YCHA}^{\mathrm{H}}$ had 18 out of $64(28.1 \%)$ compared to 7 out of $55(12.7 \%)$ of upregulated metabolism-related proteins (Figures $3(\mathrm{al})$ and $3(\mathrm{cl})$ ). The $\mathrm{OCHA}^{\mathrm{L}}$ maintained a high percentage of $20.8 \%$ metabolism-related proteins compared to OTCS ${ }^{\mathrm{H}}$ (Figure 3(b1)). The OTCS ${ }^{\mathrm{H}}: \mathrm{YTCS}^{\mathrm{L}}$ had $38.2 \%$ for signal transduction and $30.9 \%$ for structural proteins compared to $25 \%$ signal transduction and $12.5 \%$ structural proteins in $\mathrm{OCHA}^{\mathrm{L}}: \mathrm{YCHA}^{\mathrm{H}}$ (Figures 3(a1) and $3(\mathrm{cl}))$. In contrary, $43.5 \%$ for signal transduction and $10.9 \%$ structural proteins were downregulated in $\mathrm{OCHA}^{\mathrm{L}}$ :OTCS ${ }^{\mathrm{H}}$ (Figure 3(b2)). To represent the distribution cloud of abundant proteins identified, normalized heavy to light $(\mathrm{H} / \mathrm{L})$ ratios were plotted against peptide intensities for the groups

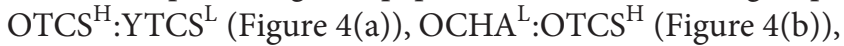
and $\mathrm{OCHA}^{\mathrm{L}}$ :YCHA ${ }^{\mathrm{H}}$ (Figure 4(c)). Each of the identified upor down regulated proteins with significance $B$ value between 0.01 and 0.001 was labeled with gene names (Figures 4(a)$4(\mathrm{c})$ ).

3.3. Downregulation of Proaging Proteins in Old Passage Cells under Hyaluronan Presence. Tables 1 and 2 show the proteins with significance $B$ value between 0.01 and 0.001 and this overlapped in the groups OTCS ${ }^{\mathrm{H}}: \mathrm{YTCS}^{\mathrm{L}}, \mathrm{OCHA}^{\mathrm{L}} \mathrm{OTCS}^{\mathrm{H}}$ and $\mathrm{OCHA}^{\mathrm{L}}: \mathrm{YCHA}^{\mathrm{H}}$. The Lamin-B1 (LMNB1) was 0.52 -fold less in $\mathrm{OCHA}^{\mathrm{L}}$ compared to $\mathrm{OTCS}^{\mathrm{H}}$. Previous study reported that nesprin-1 (SYNE1) maintained nuclear integrity and was 2.54-fold downregulated in $\mathrm{OTCS}^{\mathrm{H}}$ compared to $\mathrm{OCHA}^{\mathrm{L}}$. As for HMGA1, it was 1.61-fold downregulated in $\mathrm{OTCS}^{\mathrm{H}}$ versus $\mathrm{OCHA}^{\mathrm{L}}$. In consistency, the senescence-related protein transgelin (TAGLN) was 0.61 -fold less in $\mathrm{OCHA}^{\mathrm{L}}$ versus $\mathrm{OTCS}^{\mathrm{H}}$, and 2.1-fold higher in $\mathrm{OTCS}^{\mathrm{H}}$ versus YTCS. The CCN family protein, cysteine rich protein 61 (CYR61), was 0.35-fold less in $\mathrm{OCHA}^{\mathrm{L}}$ compared to $\mathrm{OTCS}^{\mathrm{H}}$. Furthermore, the probable fructose-2,6-bisphosphatase TIGAR (TIGAR) decrease by 0.59 -fold in $\mathrm{OTCS}^{\mathrm{H}}$ compared to YTCS $^{\mathrm{L}}$ (Table 1 ).

The Rho-related GTP-binding protein RhoE (RND3) had

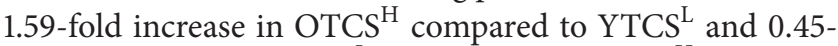
fold decrease in $\mathrm{OCHA}^{\mathrm{L}}$ compared to $\mathrm{OTCS}^{\mathrm{H}}$ (Table 1). Consistent with previous report that Lin11-Isl-1-Mec-3 or LIM domain was activated in case of RND3 upregulation [32], the actin-binding domain protein 1 (LIMA1) and four and a half LIM domains protein 1 (FHL1) had 1.52- and 3.23fold increase in OTCS ${ }^{\mathrm{H}}$ versus YTCS $^{\mathrm{L}}$, respectively (Table 1). Consistently, LIMA1 and FHL1 were 0.45 - and 0.40 -fold lower in $\mathrm{OCHA}^{\mathrm{L}}$ compared to $\mathrm{OTCS}^{\mathrm{H}}$, respectively. Furthermore, tropomyosin alpha-1 (TPM1) for cell contraction [36] was 0.6-fold lower in $\mathrm{OCHA}^{\mathrm{L}}$ versus $\mathrm{OTCS}^{\mathrm{H}}$ and 2.25-fold higher in OTCS $^{\mathrm{H}}$ versus YTCS $^{\mathrm{L}}$ (Table 1). Other actin-binding proteins were neurofilament medium polypeptide (NEFM) and filamin-C (FLNC). The OCHA ${ }^{\mathrm{L}}$ had 0.6 -fold of NEFM and 0.59 -fold of FLNC decrease versus $\mathrm{OTCS}^{\mathrm{H}}$. In addition, OTCS $^{\mathrm{H}}$ had 2.3-fold of NEFM and 1.65-fold of FLNC increase versus YTCS $^{\mathrm{L}}$ (Table 1).

3.4. Activation of Endoplasmic Reticulum-Associated Degradation Pathway Molecules in Hyaluronan Presence. The endoplasmic reticulum (ER) stress factors, protein disulfideisomerase A4 (PDIA4), endoplasmin (HSP90B1), hypoxia upregulated protein 1 (HYOU1), and $78 \mathrm{kDa}$ glucoseregulated protein (HSPA5), were 2.02-, 1.85-, 1.73-, and 1.66fold higher, respectively, in $\mathrm{OCHA}^{\mathrm{L}}$ compared to $\mathrm{OTCS}^{\mathrm{H}}$ (Table 2). The Ras-related protein RRAS2 was 0.6-fold lower in $\mathrm{OCHA}^{\mathrm{L}}$ compared to $\mathrm{OTCS}^{\mathrm{H}}$ (Table 2). And the protein degradation COP9 signalosome complex components COPS2 and COPS3 were 1.76- and 3.71-fold higher in 


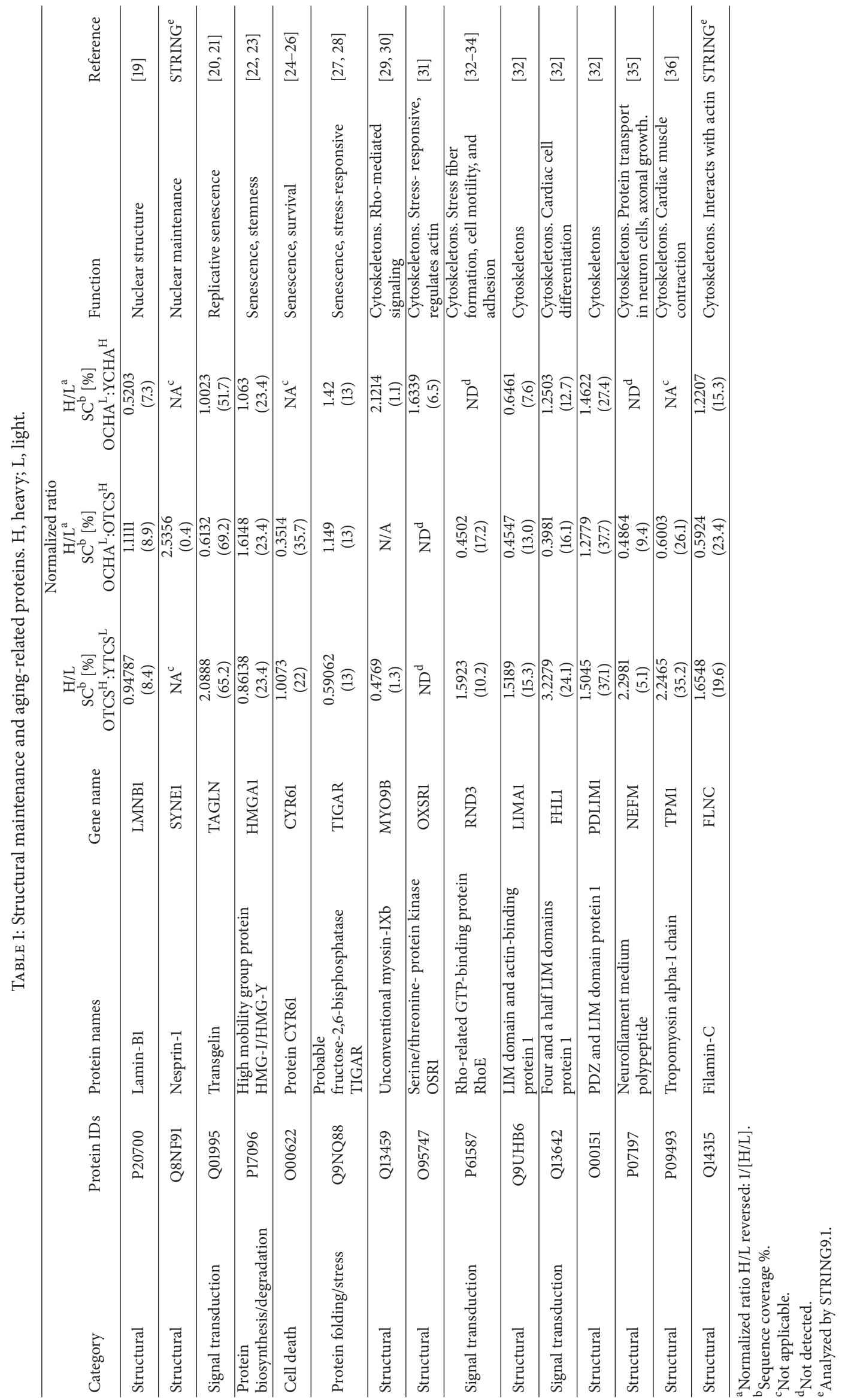




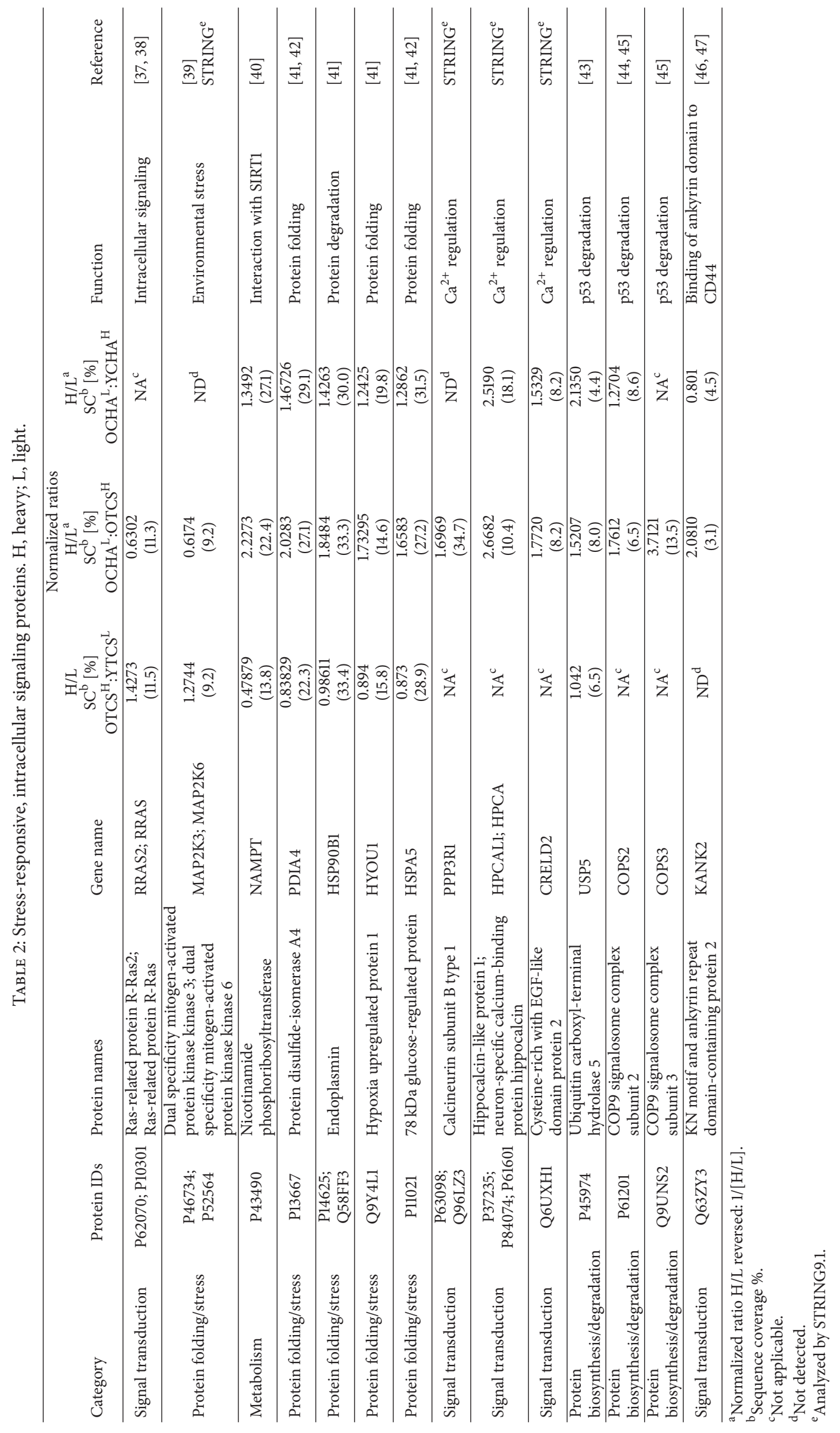



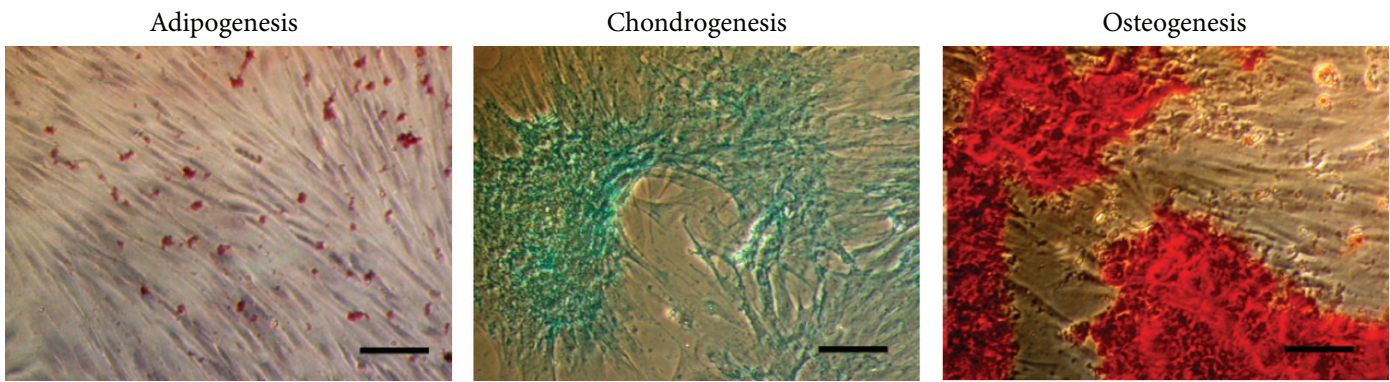

(a)
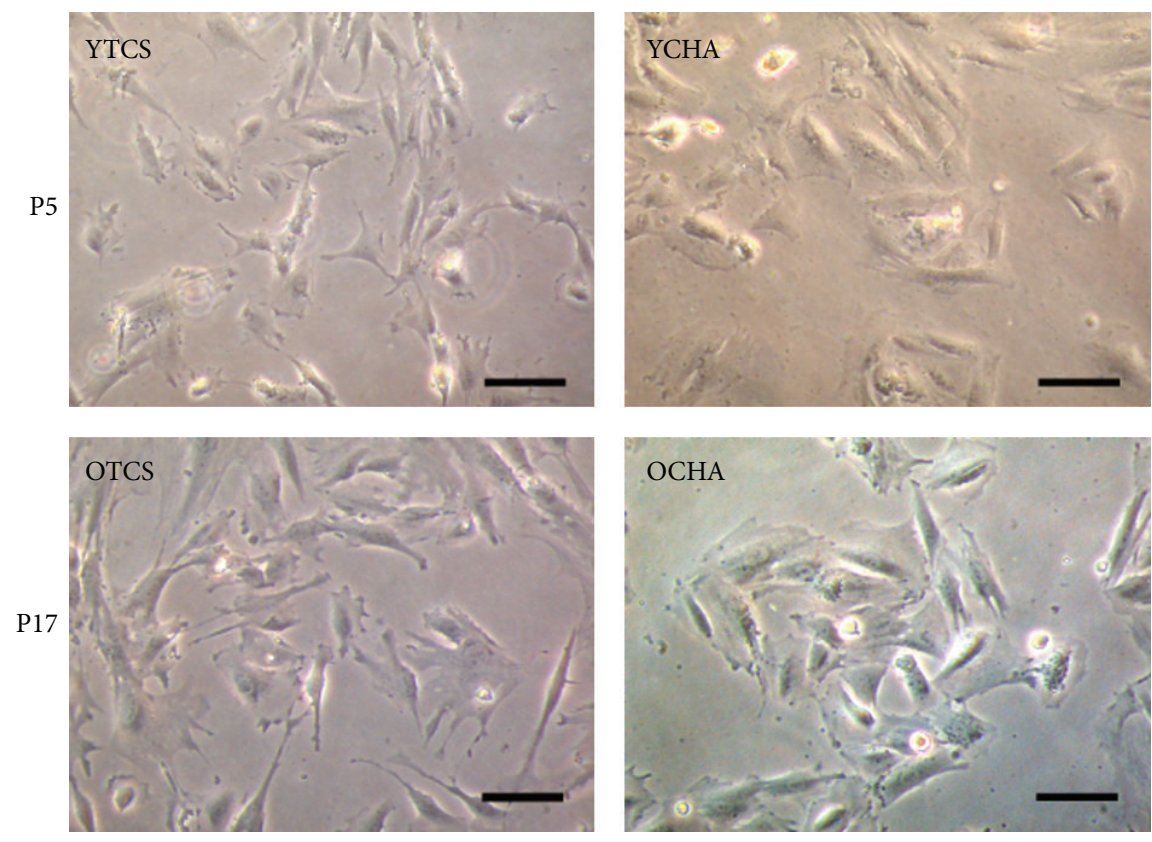

(b)

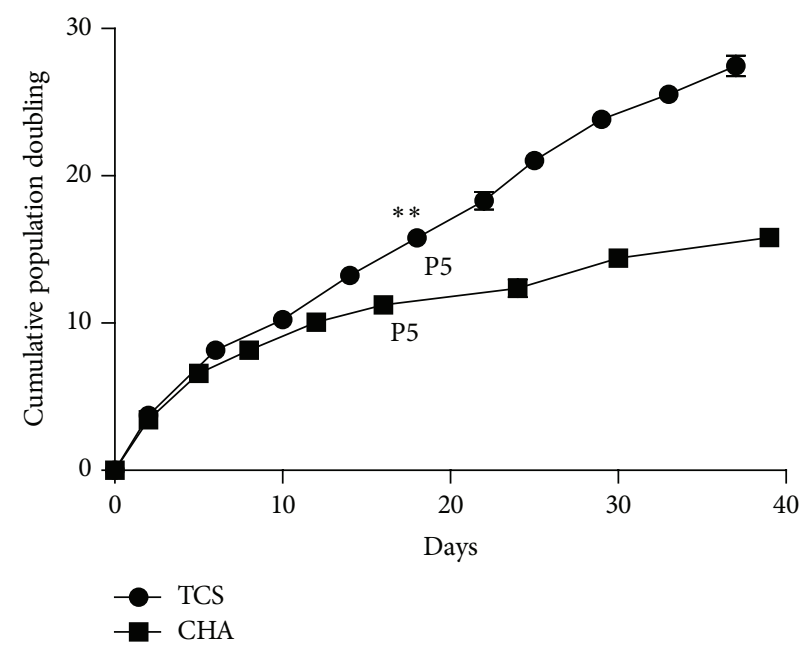

(c)

Figure 1: Hyaluronan-coated surface affected cell proliferation of PDMSC. (a) The PDMSC grown on tissue-culture polystyrene surface differentiated to adipocytes, chondrocytes, and osteocytes after induction for 4 weeks. Scale bar $=100 \mu \mathrm{m}$. (b) The PDMSC presented fibroblastic morphology on tissue-culture polystyrene surface (TCS) and formed aggregate on tissue-culture polystyrene surface coated with $30 \mu \mathrm{g} / \mathrm{mL}$ hyaluronan (CHA). The cells at P5 are noted as young and P17 as old. In CHA, the culture of PDMSC on HA-coated surface began at P2; thus, P2 3 passages (P5) and P2 +15 passages (P17) for young and old CHA, respectively. Scale bar $=100 \mu \mathrm{m}$. (c) The proliferation of PDMSC on TCS and CHA grown for a period of 5 weeks. Each of the data points represents cumulated population doubling for one passage. Three independent experiments were performed in TCS and CHA and data are represented in mean \pm SD. ${ }^{* *} P$ value $<0.01$. 


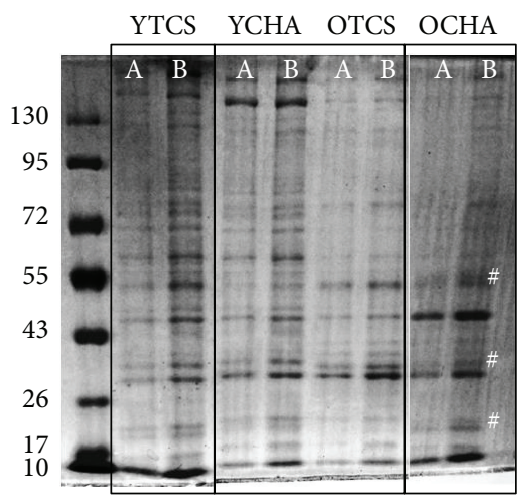

(a)

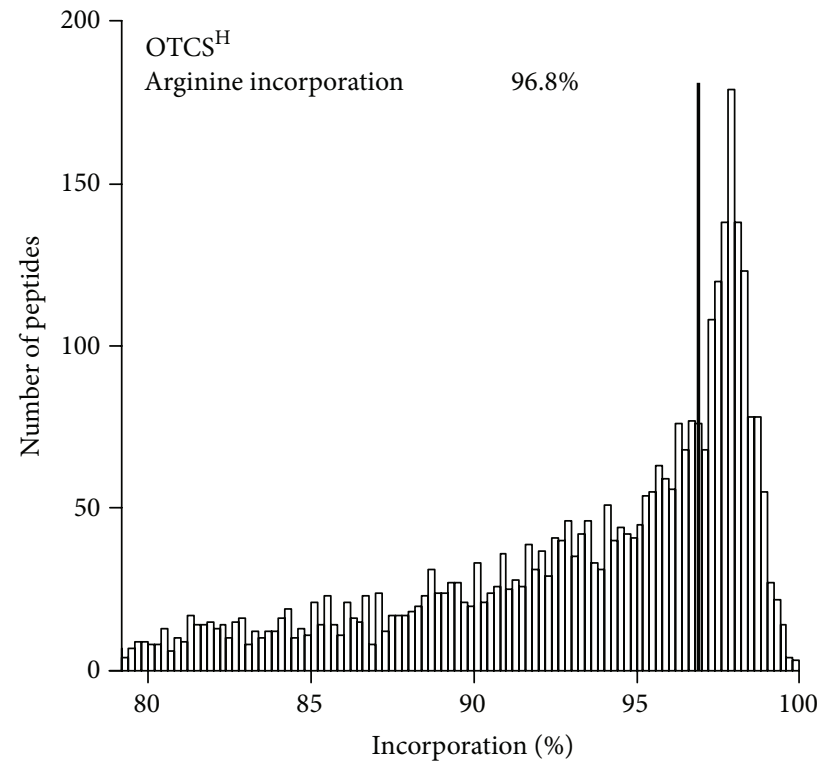

(c)

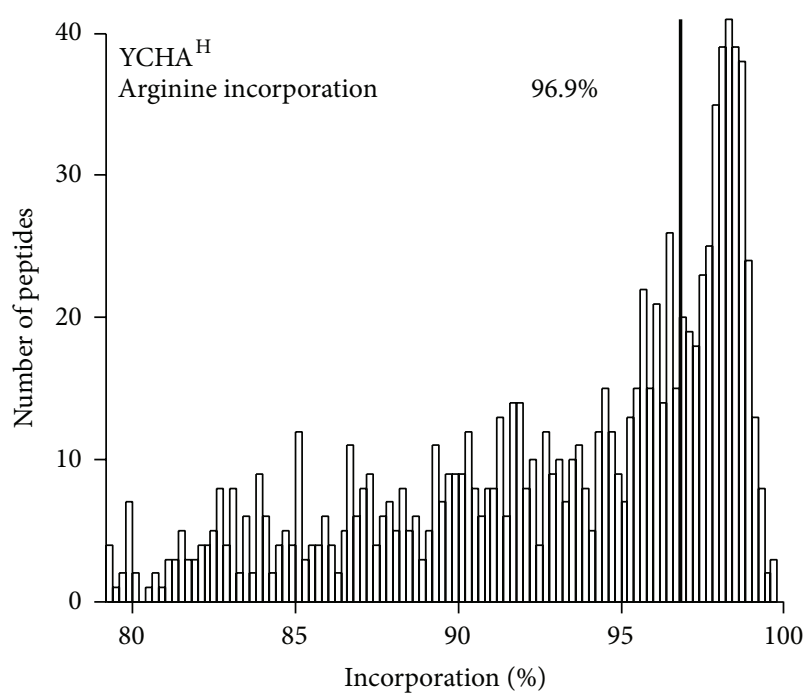

(e)

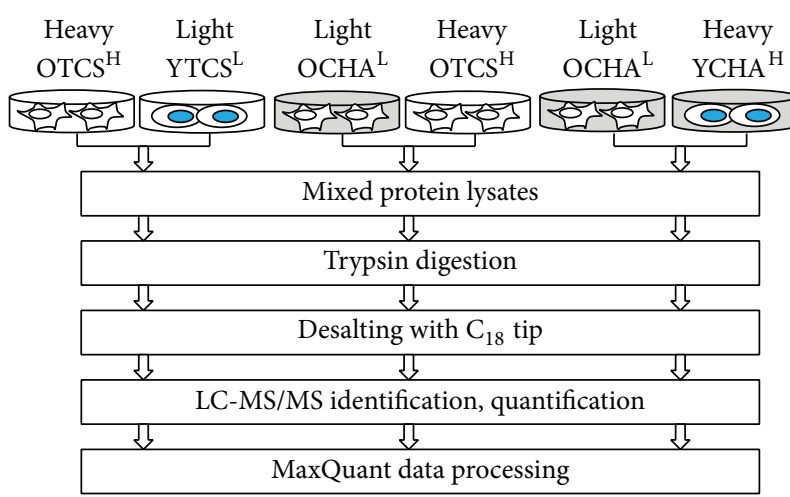

(b)

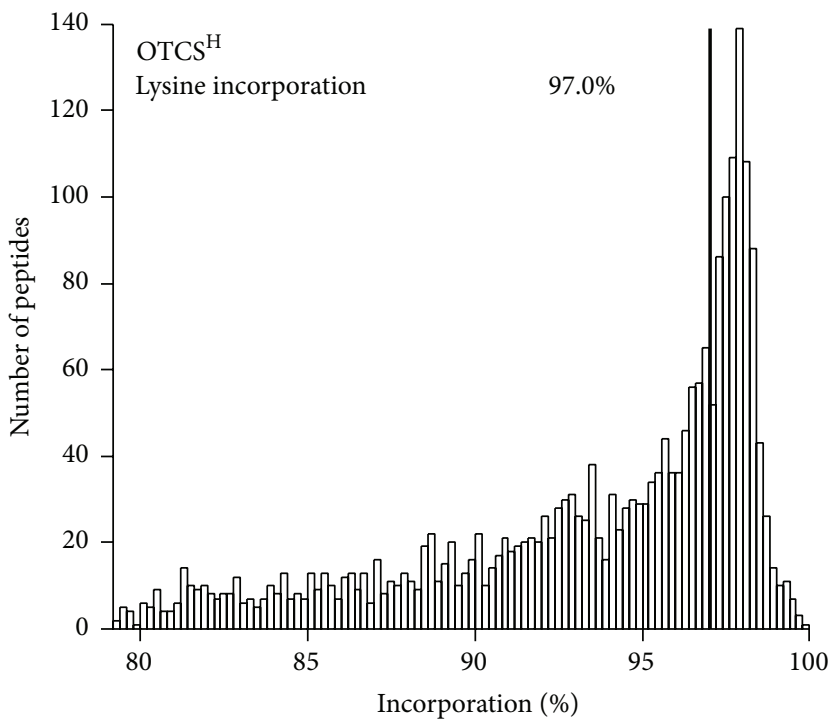

(d)

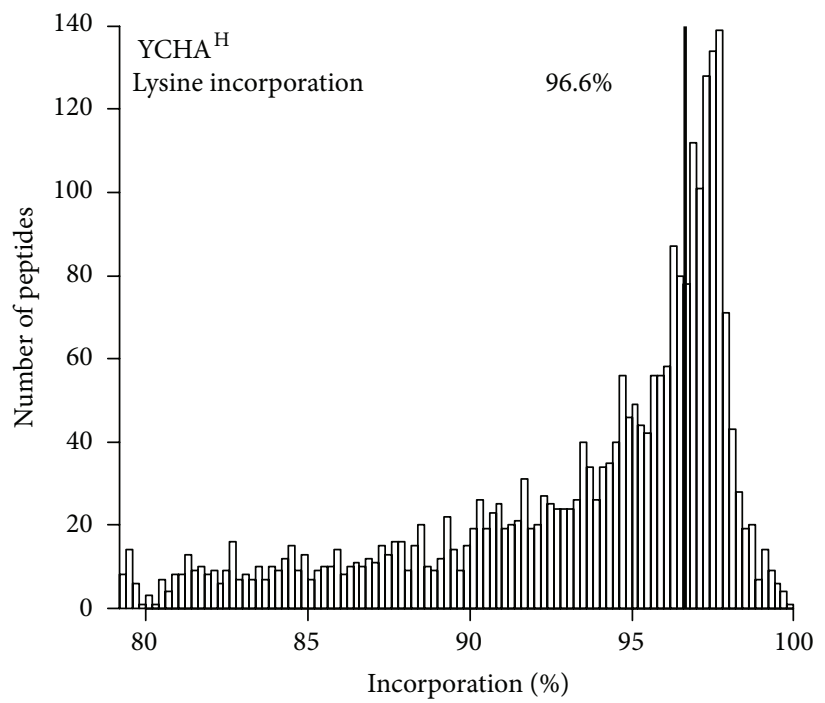

(f)

FIGURE 2: Proteomic workflow and incorporation rate of SILAC-labeled PDMSC. (a) The protein lysates collected at P5 and P17 for PDMSC cultured on TCS and CHA were separated on $8 \%$ SDS gel and stained with coomassie blue. The amounts of protein loaded were $10 \mu \mathrm{g}$ (Lane A) and $30 \mu \mathrm{g}$ (Lane B), respectively, for YTCS, YCHA, OTCS, and OCHA. The symbol (\#) represents varied protein bands in the OCHA (Lane B) compared to OTCS (Lane B). (b) The illustration shows experimental workflow. (c-d) Heavy amino acids incorporation for OTCS ${ }^{\mathrm{H}}$ after 5-6 doublings. (e-f) Heavy amino acids incorporation for $\mathrm{YCHA}^{\mathrm{H}}$ after 5-6 doublings. Incorporation efficiency of the heavy arginine and lysine for PDMSC were determined before further protein identification and quantitation analysis using LC-MS/MS. 
Total

OTCS $^{\mathrm{H}}$ versus YTCS ${ }^{\mathrm{L}}$

Total identified 965

Significance $B<0.0181$

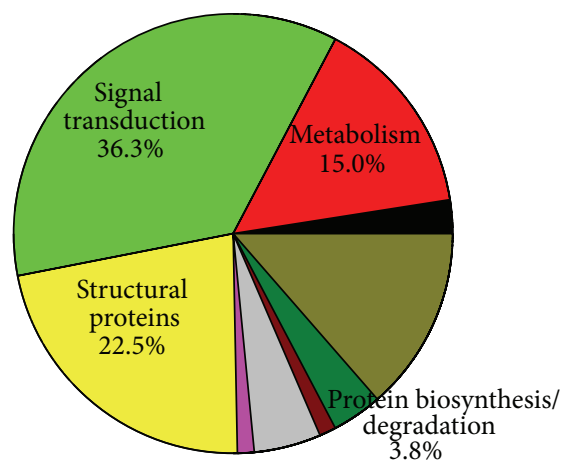

- Protein transport 2.5\%

Metabolism 15.0\%

Signal transduction $36.3 \%$

Structural proteins $22.5 \%$

$\longrightarrow$ Replication $0 \%$

Cell death $1.3 \%$

Transcription $0 \%$

Protein folding/stress 5\%

Epigenetics $1.3 \%$

Protein biosynthesis/degradation 3.8\%

○thers $13.8 \%$

(a)

Fold increase $>1.5$

OTCS $^{\mathrm{H}}$ versus YTCS ${ }^{\mathrm{L}} \quad$ Total 55

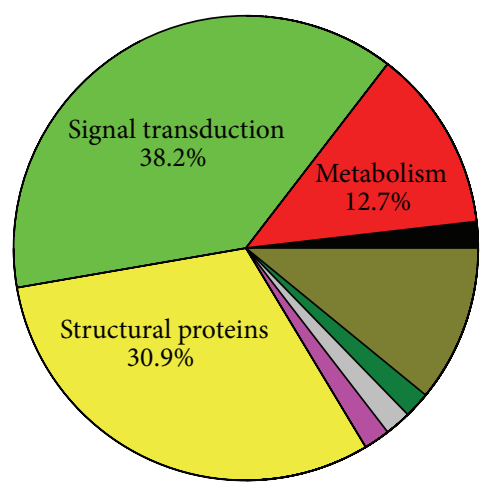

Protein transport $1.8 \%$

- Metabolism 12.7\%

- Signal transduction $38.2 \%$

— Structural proteins $30.9 \%$

Replication $0.0 \%$

Cell death $1.8 \%$

Transcription $0.0 \%$

$\sqsubset$ Protein folding/stress $1.9 \%$

Epigenetics $0.0 \%$

Protein biosynthesis/degradation $1.8 \%$

— Others $10.9 \%$

(a1)
Total

OCHA $^{\mathrm{L}}$ versus $\mathrm{OTCS}^{\mathrm{H}}$

Total identified 1038

Significance $B<0.0194$

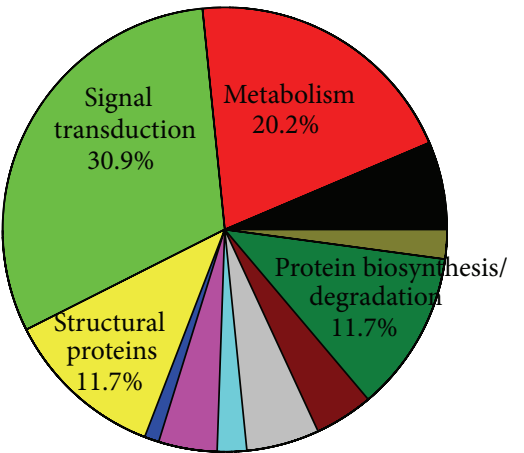

\footnotetext{
- Protein transport $6.4 \%$

— Metabolism 20.2\%

— Signal transduction $30.9 \%$

\Structural proteins $11.7 \%$

Replication $1.1 \%$

Cell death $4.3 \%$

Transcription $2.1 \%$

Protein folding/stress $5.3 \%$

Epigenetics $4.3 \%$

Protein biosynthesis/degradation 11.7\%

— Others 2.1\%
}

(b)

Fold increase $>1.5$

OCHA $^{\mathrm{L}}$ versus $\mathrm{OTCS}^{\mathrm{H}} \quad$ Total 48

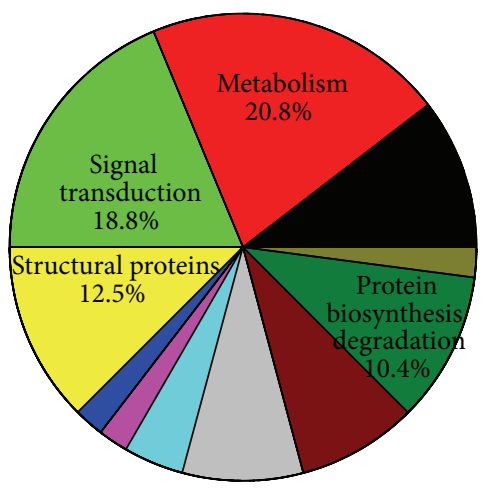

Protein transport $10.4 \%$

— Metabolism 20.8\%

Cignal transduction $18.8 \%$

Structural proteins $12.5 \%$

Replication $2.1 \%$

Cell death 2.1\%

Transcription $4.2 \%$

Protein folding/stress $8.3 \%$

Epigenetics $8.3 \%$

Protein biosynthesis/degradation $10.4 \%$

Others 2.1\%

(b1)
Total

OCHA $^{\mathrm{L}}$ versus $\mathrm{YCHA}^{\mathrm{H}}$

Total identified 916

Significance $B<0.01112$

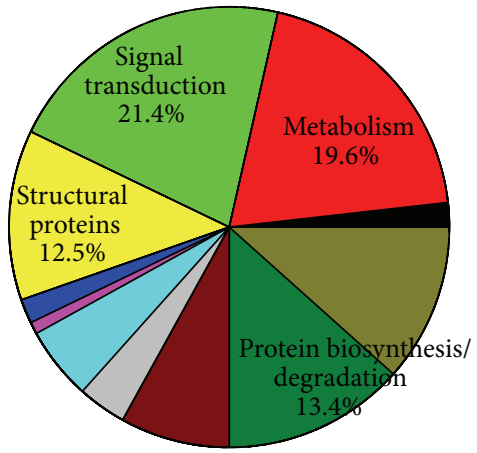

- Protein transport $1.8 \%$

- Metabolism 19.6\%

- Signal transduction $21.4 \%$

— Structural proteins $12.5 \%$

Replication $1.8 \%$

— Cell death $0.9 \%$

Transcription 5.4\%

Protein folding/stress 3.6\%

Epigenetics 8.0

- Protein biosynthesis/degradation $13.4 \%$

—others $11.6 \%$

(c)

Fold increase $>1.5$

OCHA $^{\mathrm{L}}$ versus $\mathrm{YCHA}^{\mathrm{H}} \quad$ Total 64

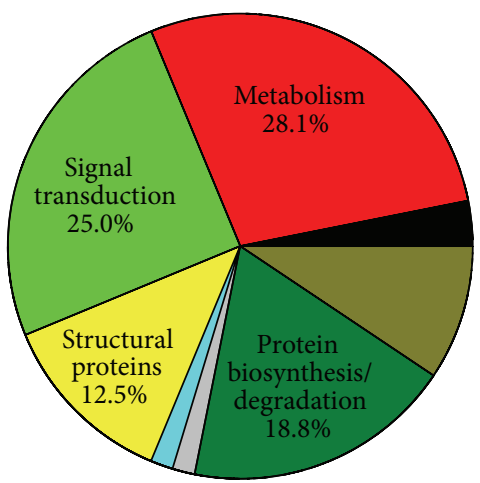

Protein transport 3.1\%

Metabolism 28.1\%

CSignal transduction $25.0 \%$

CStructural proteins $12.5 \%$

Replication $0.0 \%$

Cell death $0.0 \%$

Transcription $1.6 \%$

Protein folding/stress $1.6 \%$

Epigenetics $0.0 \%$

Protein biosynthesis/degradation $18.8 \%$

Others $9.4 \%$

(c1)

Figure 3: Continued. 
Fold decrease $>1.5$

OTCS $^{\mathrm{H}}$ versus YTCS ${ }^{\mathrm{L}} \quad$ Total 26

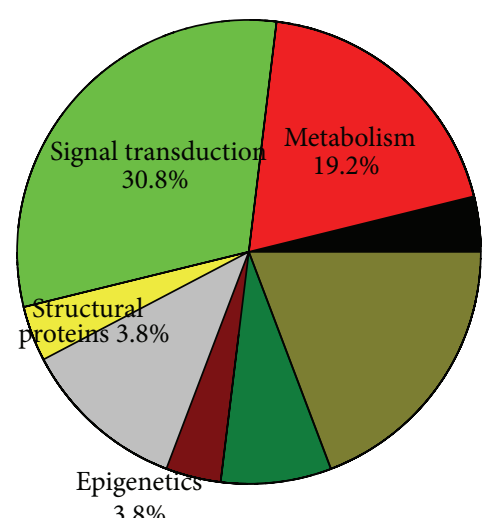

$3.8 \%$

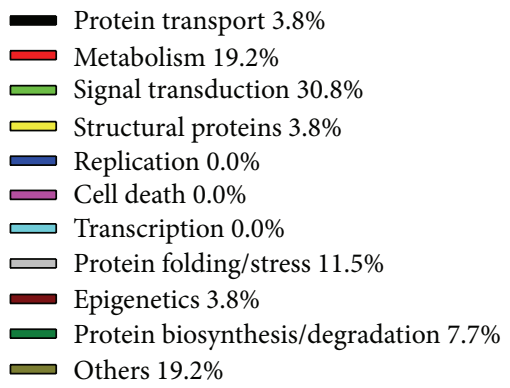

(a2)
Fold decrease $>1.5$

OCHA $^{\mathrm{L}}$ versus OTCS $^{\mathrm{H}} \quad$ Total 46

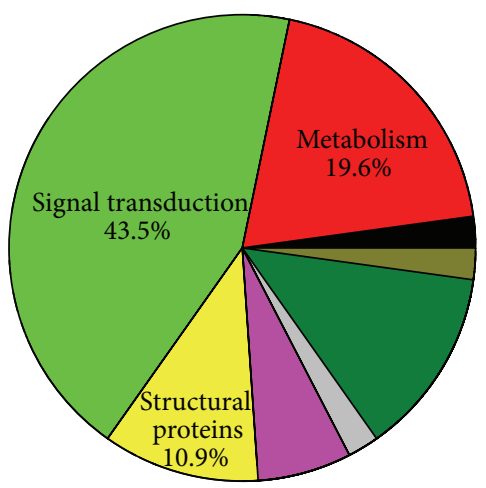

Protein transport $2.2 \%$
Metabolism $19.6 \%$
Signal transduction $43.5 \%$
Structural proteins $10.9 \%$
Replication $0.0 \%$
Cell death $6.5 \%$
Transcription $0.0 \%$
$=$ Protein folding/stress $2.2 \%$
Epigenetics $0.0 \%$
Protein biosynthesis/degradation $13.0 \%$
Others $2.2 \%$

(b2)
Fold decrease $>1.5$

OCHA $^{\mathrm{L}}$ versus YCHA $^{\mathrm{H}} \quad$ Total 48
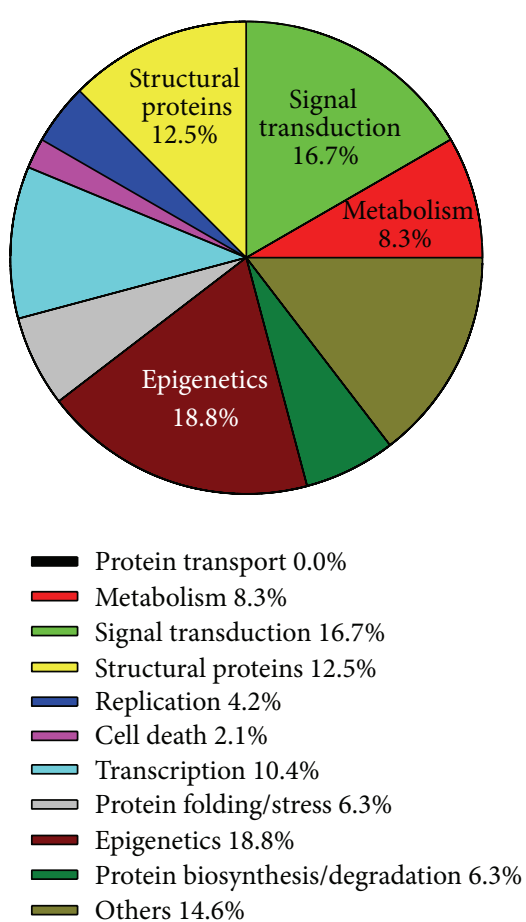

(c2)

FIGURE 3: The aging phenomena in HA absence detected high percentages of signal transduction and structural proteins. Pie charts

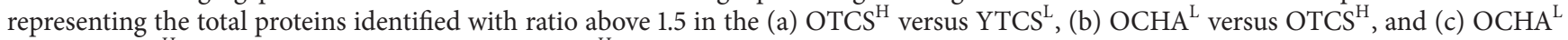
versus $\mathrm{YCHA}^{\mathrm{H}}$ groups, respectively. (a1) The $\mathrm{OTCS}^{\mathrm{H}}$ had $0 \%$ of replication-related proteins, showing that replication had slowed down or ceased. (a2) The upregulated proteins in $\mathrm{OTCS}^{\mathrm{H}}$ had $30.9 \%$ of structural proteins and $3.8 \%$ of downregulated proteins cell structural. Cell structure may have played a major role in the aging cells. (b1) In comparison to $\mathrm{OTCS}^{\mathrm{H}}$, $\mathrm{OCHA}^{\mathrm{L}}$ had $10.4 \%$ upregulated proteins of biosynthesis/degradation proteins, which correlated with the high percentage of metabolic proteins $(20.8 \%)$, indicating that $\mathrm{OCHA}^{\mathrm{L}}$ had higher metabolic activity. (b2) The group OCHA ${ }^{\mathrm{L}}$ had $43.5 \%$ downregulated proteins for signal transduction. (c1) The metabolic activity $(28.1 \%)$ in $\mathrm{OCHA}^{\mathrm{L}}$ was higher compared to $\mathrm{YCHA}^{\mathrm{H}}$, which may have correlated with the protein biosynthesis/degradation activity of $18.8 \%$. The aging phenomena in the $\mathrm{OCHA}^{\mathrm{H}}$ differed from that in $\mathrm{OTCS}^{\mathrm{H}}$ in (a1), where the upregulated $12.7 \%$ of metabolic and $1.8 \%$ biosynthesis/degradation proteins. (c2) Epigenetics consisted $18.8 \%$ of the downregulated proteins in $\mathrm{OCHA}^{\mathrm{L}}$, suggesting epigenetic regulation of cells after long-term HA presence.

$\mathrm{OCHA}^{\mathrm{L}}$ compared to $\mathrm{OTCS}^{\mathrm{H}}$ (Table 2). Additionally, the ubiquitin/proteasomal system proteins ubiquitin carboxylterminal hydroxylase 5 (USP5) was 1.52 -fold higher in $\mathrm{OCHA}^{\mathrm{L}}$ versus $\mathrm{OTCS}^{\mathrm{H}}$ (Table 2). Consistent with previous reports on the environmental stress-related protein dual specificity mitogen-activated protein kinase kinase 3, dual specificity mitogen-activated protein kinase kinase 6 (MAP2K3; MAP2K6) was 0.62-fold lower in $\mathrm{OCHA}^{\mathrm{L}}$ compared to $\mathrm{OTCS}^{\mathrm{H}}$ (Table 2). And the Nicotinamide phosphoribosyltransferase (NAMPT), a major regulator of SIRT1, was 2.23-fold higher in $\mathrm{OCHA}^{\mathrm{L}}$ compared to $\mathrm{OTCS}^{\mathrm{H}}$

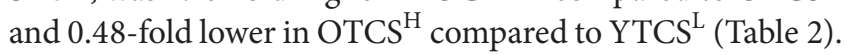

\subsection{Potential p53-Mediated Senescence Suppression Detected} under Hyaluronan Culture Condition. The hypothesized pathway of the detected aging-related molecules is depicted in Figure 5. In absence of HA, the upregulation of Ras signaling, MAP2K3; MAP2K6, and actin-interacting proteins
(RND3, LIMA1, FHL1, NEFM, TPM1, and FLNC) may have led to potential stress fiber formation, promoting senescence and aging (Figure 5(c)). However, HA presence led to the downregulation of Ras signaling, MAP2K3; MAP2K6, actininteracting proteins (RND3, LIMA1, FHL1, NEFM, TPM1, and FLNC), upregulation of NAMPT, and upregulation of ER stress chaperone molecules which is the endoplasmic reticulum-associated degradation (ERAD) pathway. The upregulated NAMPT may have prevented p53-mediated senescence through p53 degradation and thus maintained the normal phenotype of the stem cells.

\section{Discussion}

In general, MSC are maintained in quiescence state when not differentiated. However, the MSC eventually lose their stem cell functions as cells are passaged for a prolonged period of time. As the number of senescent cells is accumulated due to 


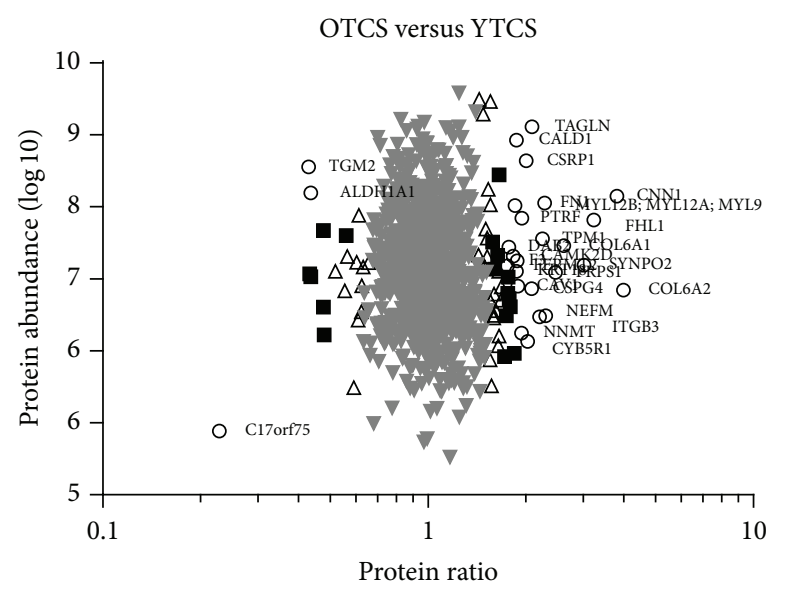

(a)

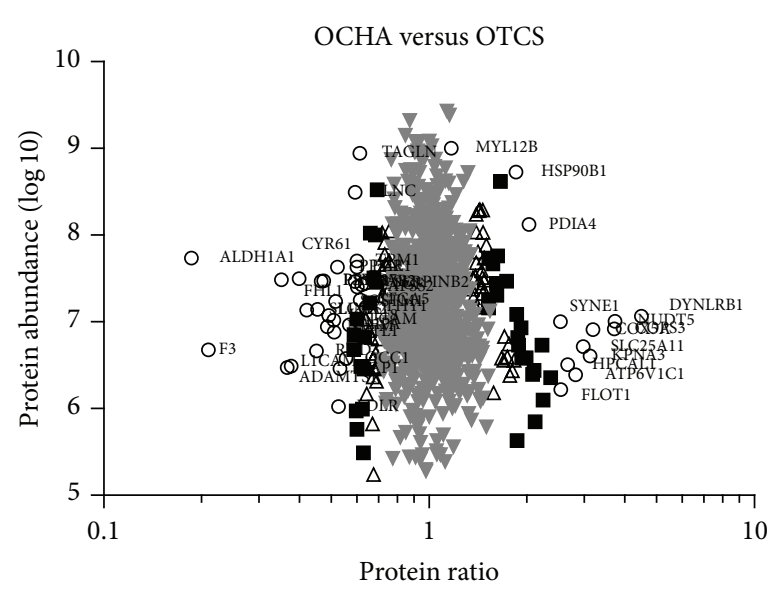

(b)

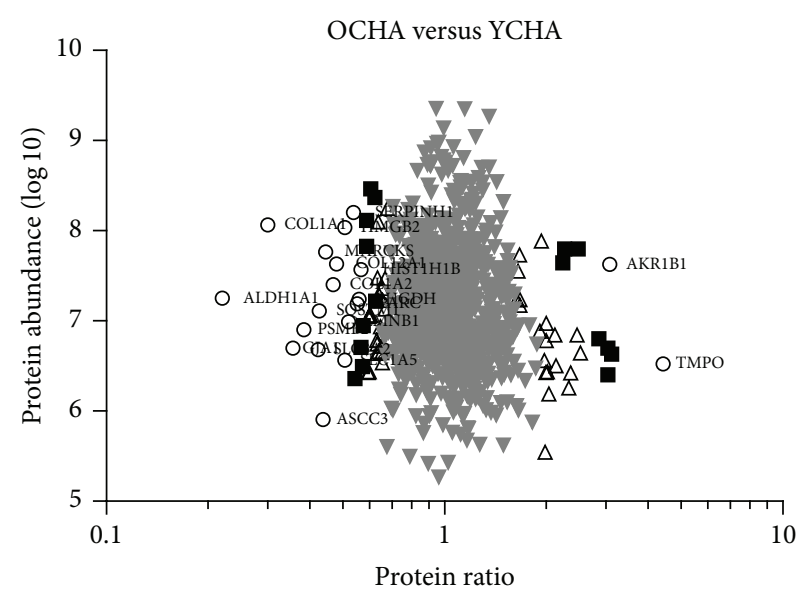

(c)

FIgURE 4: The normalized heavy- and light-labeled protein ratios plotted against total peptide intensities. The distribution of proteins identified is lower at higher abundance, confirming that protein quantification is more accurate. The data points are colored based on their significance $B$ calculated using software Perseus where the gray and black triangles represent $P$ value $>0.05$, squares $P$ value $<0.01$, and circles $P$ value $<0.001$. Abundant protein ratios for (a) OTCS ${ }^{\mathrm{H}}$ versus $\mathrm{YTCS}^{\mathrm{L}}$, (b) OCHA ${ }^{\mathrm{L}}$ versus OTCS ${ }^{\mathrm{H}}$, and $(\mathrm{c}) \mathrm{OCHA}^{\mathrm{L}}$ versus $\mathrm{YCHA}^{\mathrm{H}}$.

environmental stress upon in vitro culture, the cells are prone to aging.

Structural proteins play important role in cell motility, cell adhesion, and cell shape which include nuclear structure maintenance. The structural protein consisted of intermediate filament, microtubules, and microfilaments. It is known that nuclear structure integrity is important for stem cell maintenance. The lamin-B1 (LMNB1) maintained nuclear structure via interacting with cytoskeleton, and its downregulation may lead to full senescence. LMNB1 protein levels declined in senescent human dermal fibroblasts and keratinocytes [19]. The spectrin repeat containing nuclear envelope 1 (SYNE-1) is required for maintenance of nuclear organization and structural integrity. According to STRING9.1 analysis, LMNB1 interacts with SYNE-1, and SYNE-1 links the nuclei to cytoskeletons via interacting with the nuclear envelope and F-actin.

The transgelin (TAGLN) was reported to interact with actin [20] to regulate the actin dynamics and stress fibers during senescence. In case of oxidative stress, the actin interaction with filaments was reported to be increased accompanied by cell apoptosis in yeast [21]. In yeast, loss of the gene encoding the actin-bundling protein Scplp, which is homologue of mammalian SM22/transgelin (TAGLN), increased sensitivity to apoptosis during oxidative stress [21]. The cysteine-rich angiogenic inducer 61 CYR61, a CCN family protein that interacts with integrin, activates Racl and $\mathrm{pRb}$, which led to senescence [24]. The CCN family protein includes Cyr61 (cysteine rich protein 61), CTGF (Connective Tissue Growth Factor), and NOV (nephroblastoma overexpressed gene). The CYR61 interacted with integrin $\alpha \mathrm{V} \beta 3$ to support cell survival [25]; however, it promoted apoptosis in fibroblasts via interacting with $\alpha 6 \beta 1$ integrin [26].

The GTP-binding protein family is composed of Rho, Ras, Rab, Sarl/Arf, and Ran [48]. The Rho protein was reported to carry out three interactions in cells to form the stress fibers: (1) interacting with Rho-kinase (ROCK) and downstream LIM kinase to increase actin polymerization, (2) interacting with ROCK to stabilize actin, and (3) interacting with diaphanous (Dia) to assemble actin-myosin [32]. 


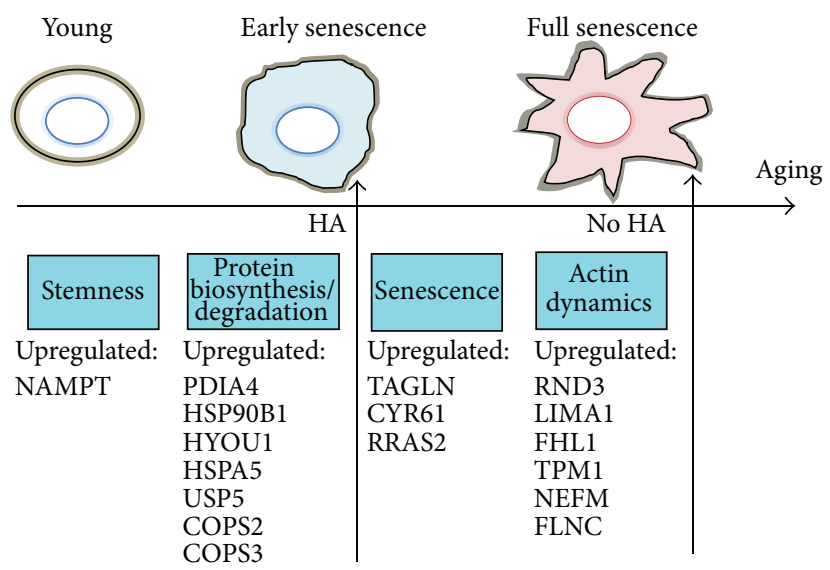

(a)
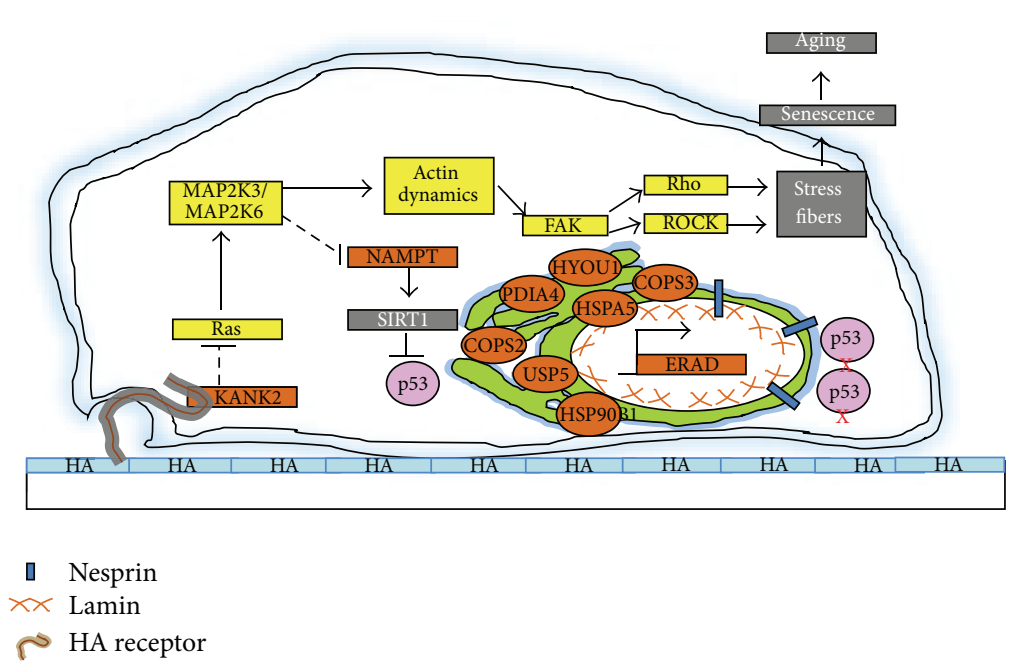

(b)

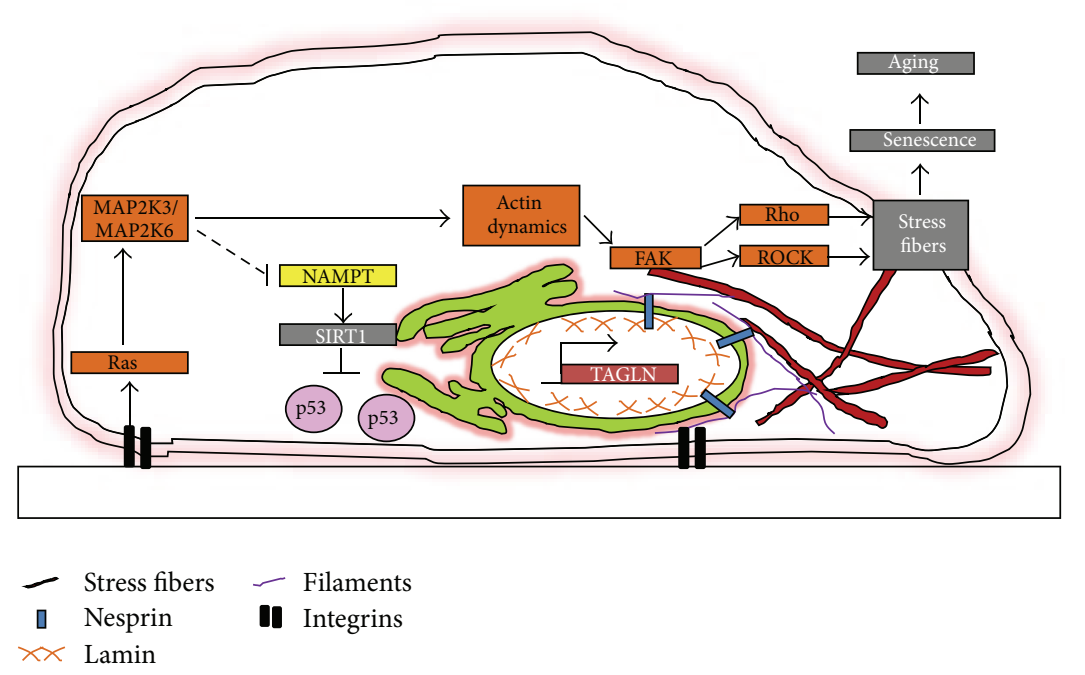

(c)

FIGURE 5: PDMSC underwent normal aging process without HA presence. (a) The aging phenomenon of PDMSC was hypothesized to be attenuated under HA presence. (b) HA was hypothesized to bind to its receptor with ankyrin repeat domain (KANK2) and suppressed the downstream actin-interacting proteins. (c) In absence of HA, the Ras signaling was hypothesized to have increased over long period of expansion and increased the downstream actin dynamics, focal adhesion kinase (FAK), stress fiber formation, and enhanced aging. Yellow boxes represented downregulation; orange boxes represented upregulation. 
During senescence, actin filaments play important role in the cell structure [21]. Senescent human diploid fibroblasts had increased actin stress fibers, focal adhesion protein rearrangement, de novo protein synthesis, and enlarged cell size [49]. The RND3 is a Rho protein known to regulate actin polymerization [32] which is involved in actincytoskeleton dynamics [48]. With regard to stress fibers and Rho expression, the increase of RND3 and other structural proteins including LIMA1, FHL1, PDLIM1, TPM1, FLNC, and NEFM indicated that PDMSC may have undergone stress fiber formation towards senescence; however, it was inhibited under HA treatment condition.

Furthermore, the GTP protein Ras is induced during senescence, with upregulation of the cell cycle arrest factor p16 [50]. Ras signaling is important for stress response [20] and normal actin remodeling [20]. The Ras signaling is regulated by adenylate cyclase (Cyrl) to produce cAMP, which activated cAMP-dependent protein kinase A (PKA), leading to expression of stress response genes in normal cells [20,37]. However, continued Ras-cAMP signaling led to abnormal actin remodeling and apoptosis during nutritional stress [20]. Previously, overexpression of Ras-cAMP inhibitor phosphodiesterase-2 (PDE2) in yeast reduced reaction oxygen species, and apoptosis, suggesting that Ras-cAMP may be induced by oxidative stress [51]. Another Ras signaling, RAS2, was found to regulate cell polarity in yeast through TPM1 and actin during temperature stress response [37].

The microenvironment confers cells to various types of environmental stresses. Whether the path to aging is due to intracellular factors or extracellular factors requires further studies. Other than nutritional stress, oxidative stress, and temperature stress mentioned above, endoplasmic reticulum stress (ER stress) was reported to be age-related [41] and is associated with upregulation of chaperones, induction of ERAD pathway, and attenuated protein translation [52]. The ER stress-responsive chaperone components include heat shock proteins [53], calnexin, calreticulin, and protein disulfide isomerases [41, 42]. Under environmental stress, normal cells utilize the ER stress components to protect from aggregation of misfolded proteins in order to maintain normal functions [41, 52]. Previous study indicated that heat shock protein $78 \mathrm{kDa}$ glucose-regulated protein (HSPA5) is a biomarker for ER stress [53] which maintained integrity of neuronal cells [54]. However, the ER stress responsive proteins were indicated to be compromised in aged cells [52, 55]. Previous study indicated that decrease in ERAD factors shortened lifespan of C. elegans [56]. In consistency, the ER stress molecules (HSP90B1, HSPA5, PDI4, and HYOU1) were upregulated in OCHA ${ }^{\mathrm{L}}$ compared to OTCS ${ }^{\mathrm{H}}$ (Table 2).

Apart from ER stress chaperones, misfolded proteins are also processed through the ubiquitin/proteasomal system (UPS). During senescence, p53 is stabilized due to DNA damage response [3], and misfolded proteins are aggregated [57]. The ER stress responsive chaperones tried to prevent secretion of misfolded proteins and stabilization of p53 $[57,58]$. It was reported that young cells possess normal protein degradation system that prevent damaged protein aggregation; however, this protein degradation system was compromised in old cells $[59,60]$. It was reported that p53 targeted and downregulated TIGAR during stress responses such as DNA damage and activation of oncogene [27], which was consistent with our data that TIGAR was decreased in $\mathrm{OTCS}^{\mathrm{H}}$ versus YTCS ${ }^{\mathrm{L}}$ (Table 2). However, the role of $\mathrm{p} 53$ is complicated such that it regulates not only DNA damage response, but also energy metabolism glycolysis and oxidative stress [61]. Previous study indicated that p53 induced TIGAR expression to reduce glycolysis [62]. It was stated that p53 promoted cell survival and tumor growth; however, HA receptor CD44 was suppressed by p53 since HA had counter effect on p53 [63]. In this case, the role of HA may have been to overcome the proaging stress inducible by p53. Similarly, the COPS2, COPS3, and USP5 which may degrade p53 were significantly upregulated in $\mathrm{OCHA}^{\mathrm{L}}$ compared to $\mathrm{OTCS}^{\mathrm{H}}$ (Table 2).

HA is produced on the cell surface by HA synthases HAS1, HAS2, and HAS3 located in plasma membrane. The role of HA varies from normal stem cells to cancer cells. HA is known to play a role in wound repair without scar in fetal tissue [64]. Previous study indicated that endogenous HA regulated differentiation of embryonic stem cells [65]. Another previous study showed that HA-coated surface enhanced chondrogenesis [66]. Normal cells produced HA and secreted into the extracellular matrix; however, they altered structure of HA activated ERK1/2 to promote senescence [67]. In contrary, HA given in the form of hydrogel was shown to maintain self-renewal of embryonic stem cells [68]. Apart from this, HA presence provided stem cells with a hypoxic microenvironment upon cell culture for embryonic stem cells [69]. Although HA is a major component of extracellular matrix, the evidence of how HA is associated with stem cells maintenance is still lacking. According to study, stem cells reside in niche with hypoxic conditions $[69,70]$. For spermatozoa and oocytes, HA was reported to maintain genome integrity [69], suggesting that HA confers stem cells functional maintenance. Based on our findings, HA may have downregulated the proaging protein TAGLN and the actin-interacting proteins RND3, LIMA1, FHL1, PDLIM1, TPM1, FLNC, and NEFM to maintain youthful cell structure. In addition, HA may have maintained normal PDMSC phenotype with the increase in ER stress factors to attenuate aging.

\section{Conflict of Interests}

The authors of this research study declared that there is no conflict of interests regarding the publication of this study.

\section{Authors' Contribution}

Tzyy Yue Wong and Ying-Hui Chen contributed equally to this work.

\section{Acknowledgments}

The authors thank Academia Sinica for instrument and technical help at the Institute of Biological Chemistry and also Professor Ueng-Cheng Yang at Institute of Biomedical 
Informatics, National Yang Ming University, for help in the data analysis. This work was supported by National Science Council NSC 95-2745-B-006-003-MY2.

\section{References}

[1] J. Campisi, "Replicative senescence: an old lives' tale?" Cell, vol. 84, no. 4, pp. 497-500, 1996.

[2] J. M. Van Deursen, "The role of senescent cells in ageing," Nature, vol. 509, no. 7501, pp. 439-446, 2014.

[3] J. Campisi and F. D. A. Di Fagagna, "Cellular senescence: when bad things happen to good cells," Nature Reviews Molecular Cell Biology, vol. 8, no. 9, pp. 729-740, 2007.

[4] L. Hayflick and P. S. Moorhead, "The serial cultivation of human diploid cell strains," Experimental Cell Research, vol. 25, no. 3, pp. 585-621, 1961.

[5] G. Pegoraro and T. Misteli, "The central role of chromatin maintenance in aging," Aging, vol. 1, no. 12, pp. 1017-1022, 2009.

[6] N. E. Sharpless and R. A. DePinho, "How stem cells age and why this makes us grow old," Nature Reviews Molecular Cell Biology, vol. 8, no. 9, pp. 703-713, 2007.

[7] N.-G. Larsson, "Somatic mitochondrial DNA mutations in mammalian aging," Annual Review of Biochemistry, vol. 79, pp. 683-706, 2010.

[8] O. Moiseeva, V. Bourdeau, A. Roux, X. Deschênes-Simard, and G. Ferbeyre, "Mitochondrial dysfunction contributes to oncogene-induced senescence," Molecular and Cellular Biology, vol. 29, no. 16, pp. 4495-4507, 2009.

[9] C. López-Otín, M. A. Blasco, L. Partridge, M. Serrano, and G. Kroemer, “The hallmarks of aging," Cell, vol. 153, no. 6, pp. 11941217, 2013.

[10] A. G. Bodnar, M. Ouellette, M. Frolkis et al., "Extension of lifespan by introduction of telomerase into normal human cells," Science, vol. 279, no. 5349, pp. 349-352, 1998.

[11] K. Cao, C. D. Blair, D. A. Faddah et al., "Progerin and telomere dysfunction collaborate to trigger cellular senescence in normal human fibroblasts," The Journal of Clinical Investigation, vol. 121, no. 7, pp. 2833-2844, 2011.

[12] D. J. Rossi, C. H. M. Jamieson, and I. L. Weissman, "Stems cells and the pathways to aging and cancer," Cell, vol. 132, no. 4, pp. 681-696, 2008.

[13] J. Halaschek-Wiener and A. Brooks-Wilson, "Progeria of stem cells: stem cell exhaustion in Hutchinson-Gilford progeria syndrome," Journals of Gerontology Series A: Biological Sciences and Medical Sciences, vol. 62, no. 1, pp. 3-8, 2007.

[14] G. Kasper, L. Mao, S. Geissler et al., "Insights into mesenchymal stem cell aging: involvement of antioxidant defense and actin cytoskeleton," STEM CELLS, vol. 27, no. 6, pp. 1288-1297, 2009.

[15] C.-M. Liu, C.-H. Yu, C.-H. Chang, C.-C. Hsu, and L. L. H. Huang, "Hyaluronan substratum holds mesenchymal stem cells in slow-cycling mode by prolonging G1 phase," Cell and Tissue Research, vol. 334, no. 3, pp. 435-443, 2008.

[16] C.-M. Liu, C.-H. Chang, C.-H. Yu, C.-C. Hsu, and L. L. H. Huang, "Hyaluronan substratum induces multidrug resistance in human mesenchymal stem cells via CD44 signaling," Cell and Tissue Research, vol. 336, no. 3, pp. 465-475, 2009.

[17] P.-Y. Chen, L. L. H. Huang, and H.-J. Hsieh, "Hyaluronan preserves the proliferation and differentiation potentials of long-term cultured murine adipose-derived stromal cells," Biochemical and Biophysical Research Communications, vol. 360, no. 1, pp. 1-6, 2007.
[18] S.-E. Ong and M. Mann, "A practical recipe for stable isotope labeling by amino acids in cell culture (SILAC)," Nature Protocols, vol. 1, no. 6, pp. 2650-2660, 2007.

[19] O. Dreesen, A. Chojnowski, P. F. Ong et al., "Lamin B1 fluctuations have differential effects on cellular proliferation and senescence," The Journal of Cell Biology, vol. 200, no. 5, pp. 605617, 2013.

[20] C. W. Gourlay and K. R. Ayscough, “The actin cytoskeleton: a key regulator of apoptosis and ageing?" Nature Reviews Molecular Cell Biology, vol. 6, no. 7, pp. 583-589, 2005.

[21] J. E. Leadsham, V. N. Kotiadis, D. J. Tarrant, and C. W. Gourlay, "Apoptosis and the yeast actin cytoskeleton," Cell Death and Differentiation, vol. 17, no. 5, pp. 754-762, 2010.

[22] A. Prieur, E. Besnard, A. Babled, and J.-M. Lemaitre, "P53 and p16INK4A independent induction of senescence by chromatindependent alteration of S-phase progression," Nature Communications, vol. 2, article 473, 2011.

[23] S. N. Shah, C. Kerr, L. Cope et al., "HMGA1 reprograms somatic cells into pluripotent stem cells by inducing stem cell transcriptional networks," PLoS ONE, vol. 7, no. 11, Article ID e48533, 2012.

[24] J.-I. Jun and L. F. Lau, "Taking aim at the extracellular matrix: CCN proteins as emerging therapeutic targets," Nature Reviews Drug Discovery, vol. 10, no. 12, pp. 945-963, 2011.

[25] C.-C. Chen and L. F. Lau, "Functions and mechanisms of action of CCN matricellular proteins," The International Journal of Biochemistry and Cell Biology, vol. 41, no. 4, pp. 771-783, 2009.

[26] V. Todoroviç, C.-C. Chen, N. Hay, and L. F. Lau, "The matrix protein CCN1 (CYR61) induces apoptosis in fibroblasts," The Journal of Cell Biology, vol. 171, no. 3, pp. 559-568, 2005.

[27] S. M. Reed and D. E. Quelle, "P53 acetylation: regulation and consequences," Cancers, vol. 7, no. 1, pp. 30-69, 2014.

[28] D. R. Green and J. E. Chipuk, "p53 and metabolism: inside the TIGAR," Cell, vol. 126, no. 1, pp. 30-32, 2006.

[29] P. L. Post, G. M. Bokoch, and M. S. Mooseker, "Human myosinIXb is a mechanochemically active motor and a GAP for rho," Journal of Cell Science, vol. 111, no. 7, pp. 941-950, 1998.

[30] J. L. Maravillas-Montero and L. Santos-Argumedo, "The myosin family: unconventional roles of actin-dependent molecular motors in immune cells," Journal of Leukocyte Biology, vol. 91, no. 1, pp. 35-46, 2012.

[31] A. Salminen and K. Kaarniranta, "AMP-activated protein kinase (AMPK) controls the aging process via an integrated signaling network," Ageing Research Reviews, vol. 11, no. 2, pp. 230-241, 2012.

[32] A. L. Bishop and A. Hall, "Rho GTPases and their effector proteins," Biochemical Journal, vol. 348, no. 2, pp. 241-255, 2000.

[33] A. Hall, "Rho GTpases and the actin cytoskeleton," Science, vol. 279, no. 5350, pp. 509-514, 1998.

[34] Y. Takai, T. Sasaki, K. Tanaka, and H. Nakanishi, "Rho as a regulator of the cytoskeleton," Trends in Biochemical Sciences, vol. 20, no. 6, pp. 227-231, 1995.

[35] Q. Liu, F. Xie, S. L. Siedlak et al., "Neurofilament proteins in neurodegenerative diseases," Cellular and Molecular Life Sciences, vol. 61, no. 24, pp. 3057-3075, 2004.

[36] P. D. Arora, P. A. Janmey, and C. A. G. McCulloch, "A role for gelsolin in stress fiber-dependent cell contraction," Experimental Cell Research, vol. 250, no. 1, pp. 155-167, 1999.

[37] J. Ho and A. Bretscher, "Ras regulates the polarity of the yeast actin cytoskeleton through the stress response pathway," Molecular Biology of the Cell, vol. 12, no. 6, pp. 1541-1555, 2001. 
[38] E. Flex, M. Jaiswal, F. Pantaleoni et al., "Activating mutations in RRAS underlie a phenotype within the RASopathy spectrum and contribute to leukaemogenesis," Human Molecular Genetics, vol. 23, no. 16, pp. 4315-4327, 2014.

[39] R. K. Schmidt-Ullrich, P. Dent, S. Grant, R. B. Mikkelsen, and K. Valerie, "Signal transduction and cellular radiation responses," Radiation Research, vol. 153, no. 3, pp. 245-257, 2000.

[40] S. Imai and J. Yoshino, "The importance of NAMPT/NAD/ SIRT1 in the systemic regulation of metabolism and ageing," Diabetes, Obesity and Metabolism, vol. 15, no. 3, pp. 26-33, 2013.

[41] M. K. Brown and N. Naidoo, "The endoplasmic reticulum stress response in aging and age-related diseases," Frontiers in Physiology, vol. 3, article 263, 2012.

[42] M. A. McGuckin, R. D. Eri, I. Das, R. Lourie, and T. H. Florin, "ER stress and the unfolded protein response in intestinal inflammation," American Journal of PhysiologyGastrointestinal and Liver Physiology, vol. 298, no. 6, pp. G820G832, 2010.

[43] S. Dayal, A. Sparks, J. Jacob, N. Allende-Vega, D. P. Lane, and M. K. Saville, "Suppression of the deubiquitinating enzyme USP5 causes the accumulation of unanchored polyubiquitin and the activation of p53," The Journal of Biological Chemistry, vol. 284, no. 8, pp. 5030-5041, 2009.

[44] K. Lykke-Andersen, L. Schaefer, S. Menon, X.-W. Deng, J. B. Miller, and N. Wei, "Disruption of the COP9 signalosome Csn2 subunit in mice causes deficient cell proliferation, accumulation of p53 and cyclin E, and early embryonic death," Molecular and Cellular Biology, vol. 23, no. 19, pp. 6790-6797, 2003.

[45] A. Peth, C. Berndt, W. Henke, and W. Dubiel, "Downregulation of COP9 signalosome subunits differentially affects the CSN complex and target protein stability," BMC Biochemistry, vol. 8, article 27, 2007.

[46] P. A. Singleton and L. Y. W. Bourguignon, "CD44 interaction with ankyrin and IP3 receptor in lipid rafts promotes hyaluronan-mediated $\mathrm{Ca}^{2+}$ signaling leading to nitric oxide production and endothelial cell adhesion and proliferation," Experimental Cell Research, vol. 295, no. 1, pp. 102-118, 2004.

[47] V. B. Lokeshwar, N. Fregien, and L. Y. W. Bourguignon, "Ankyrin-binding domain of CD44(GP85) is required for the expression of hyaluronic acid-mediated adhesion function," The Journal of Cell Biology, vol. 126, no. 4, pp. 1099-1109, 1994.

[48] Y. Takai, T. Sasaki, and T. Matozaki, "Small GTP-binding proteins," Physiological Reviews, vol. 81, no. 1, pp. 153-208, 2001.

[49] Q. M. Chen, V. C. Tu, J. Catania, M. Burton, O. Toussaint, and $\mathrm{T}$. Dilley, "Involvement of $\mathrm{Rb}$ family proteins, focal adhesion proteins and protein synthesis in senescent morphogenesis induced by hydrogen peroxide," Journal of Cell Science, vol. 113, no. 22, pp. 4087-4097, 2000.

[50] T. J. Huot, J. Rowe, M. Harland et al., "Biallelic mutations in p16INK4a confer resistance to Ras- and Ets-induced senescence in human diploid fibroblasts," Molecular and Cellular Biology, vol. 22, no. 23, pp. 8135-8143, 2002.

[51] C. W. Gourlay and K. R. Ayscough, "Identification of an upstream regulatory pathway controlling actin-mediated apoptosis in yeast," Journal of Cell Science, vol. 118, no. 10, pp. 21192132, 2005.

[52] N. Naidoo, "ER and aging — protein folding and the ER stress response," Ageing Research Reviews, vol. 8, no. 3, pp. 150-159, 2009.
[53] Y. Kozutsumi, M. Segal, K. Normington, M.-J. Gething, and J. Sambrook, "The presence of malfolded proteins in the endoplasmic reticulum signals the induction of glucose-regulated proteins," Nature, vol. 332, no. 6163, pp. 462-464, 1988.

[54] Z. Yu, H. Luo, W. Fu, and M. P. Mattson, “The endoplasmic reticulum stress-responsive protein GRP78 protects neurons against excitotoxicity and apoptosis: suppression of oxidative stress and stabilization of calcium homeostasis," Experimental Neurology, vol. 155, no. 2, pp. 302-314, 1999.

[55] J. E. Nuss, K. B. Choksi, J. H. DeFord, and J. Papaconstantinou, "Decreased enzyme activities of chaperones PDI and BiP in aged mouse livers," Biochemical and Biophysical Research Communications, vol. 365, no. 2, pp. 355-361, 2008.

[56] P. J. Lim, R. Danner, J. Liang et al., "Ubiquilin and p97/VCP bind erasin, forming a complex involved in ERAD," Journal of Cell Biology, vol. 187, no. 2, pp. 201-217, 2009.

[57] S. Wakabayashi and H. Yoshida, "The essential biology of the endoplasmic reticulum stress response for structural and computational biologists," Computational and Structural Biotechnology Journal, vol. 6, no. 7, pp. 1-9, 2013.

[58] O. Pluquet, L.-K. Qu, D. Baltzis, and A. E. Koromilas, "Endoplasmic reticulum stress accelerates p53 degradation by the cooperative actions of $\mathrm{Hdm} 2$ and glycogen synthase kinase $3 \beta$," Molecular and Cellular Biology, vol. 25, no. 21, pp. 9392-9405, 2005.

[59] M. Martinez-Vicente, G. Sovak, and A. M. Cuervo, "Protein degradation and aging," Experimental Gerontology, vol. 40, no. 8-9, pp. 622-633, 2005.

[60] É. Kevei and T. Hoppe, "Ubiquitin sets the timer: impacts on aging and longevity," Nature Structural and Molecular Biology, vol. 21, no. 4, pp. 290-292, 2014.

[61] A. M. Puzio-Kuter, "The role of p53 in metabolic regulation," Genes \& Cancer, vol. 2, no. 4, pp. 385-391, 2011.

[62] K. Bensaad, A. Tsuruta, M. A. Selak et al., "TIGAR, a p53inducible regulator of glycolysis and apoptosis," Cell, vol. 126, no. 1, pp. 107-120, 2006.

[63] S. Godar, T. A. Ince, G. W. Bell et al., "Growth-inhibitory and tumor-suppressive functions of p53 depend on its repression of CD44 expression," Cell, vol. 134, no. 1, pp. 62-73, 2008.

[64] K. Kishi, K. Okabe, R. Shimizu, and Y. Kubota, "Fetal skin possesses the ability to regenerate completely: complete regeneration of skin," The Keio Journal of Medicine, vol. 61, no. 4, pp. 101-108, 2012.

[65] S. Shukla, R. Nair, M. W. Rolle et al., "Synthesis and organization of hyaluronan and versican by embryonic stem cells undergoing embryoid body differentiation," Journal of Histochemistry and Cytochemistry, vol. 58, no. 4, pp. 345-358, 2010.

[66] S.-C. Wu, J.-K. Chang, C.-K. Wang, G.-J. Wang, and M.-L. Ho, "Enhancement of chondrogenesis of human adipose derived stem cells in a hyaluronan-enriched microenvironment," Biomaterials, vol. 31, no. 4, pp. 631-640, 2010.

[67] K. Suwan, K. Choocheep, S. Hatano, P. Kongtawelert, K. Kimata, and $\mathrm{H}$. Watanabe, "Versican/PG-M assembles hyaluronan into extracellular matrix and inhibits CD44-mediated signaling toward premature senescence in embryonic fibroblasts," The Journal of Biological Chemistry, vol. 284, no. 13, pp. 8596-8604, 2009.

[68] S. Gerecht, J. A. Burdick, L. S. Ferreira, S. A. Townsend, R. Langer, and G. Vunjak-Novakovic, "Hyaluronic acid hydrogel for controlled self-renewal and differentiation of human embryonic stem cells," Proceedings of the National Academy of Sciences 
of the United States of America, vol. 104, no. 27, pp. 11298-11303, 2007.

[69] Z. Darzynkiewicz and E. A. Balazs, "Genome integrity, stem cells and hyaluronan," Aging, vol. 4, no. 2, pp. 78-88, 2012.

[70] A. Mohyeldin, T. Garzón-Muvdi, and A. Quiñones-Hinojosa, "Oxygen in stem cell biology: a critical component of the stem cell niche," Cell Stem Cell, vol. 7, no. 2, pp. 150-161, 2010. 

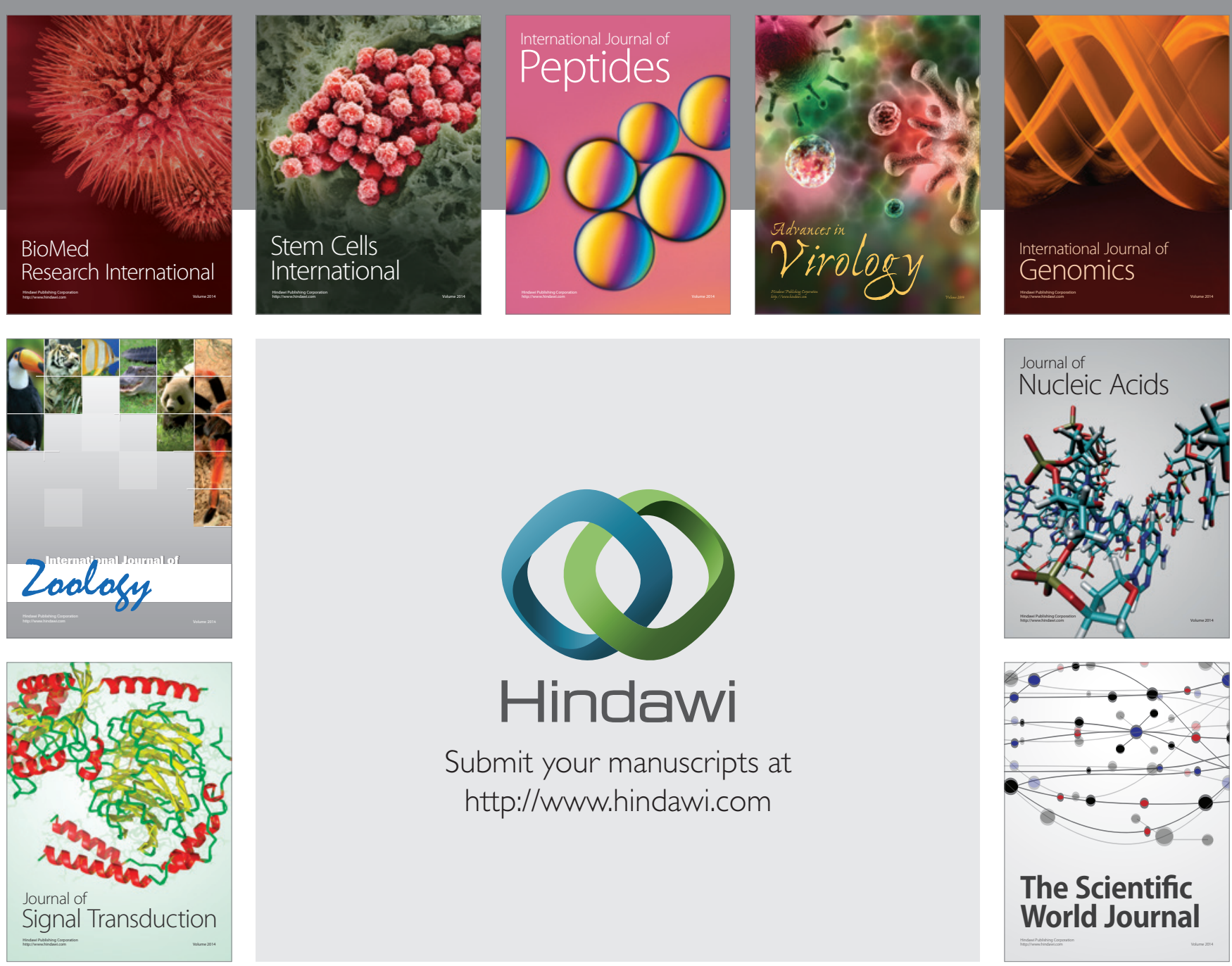

Submit your manuscripts at

http://www.hindawi.com
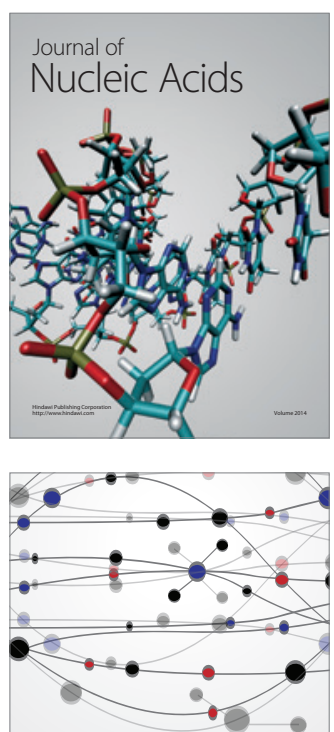

The Scientific World Journal
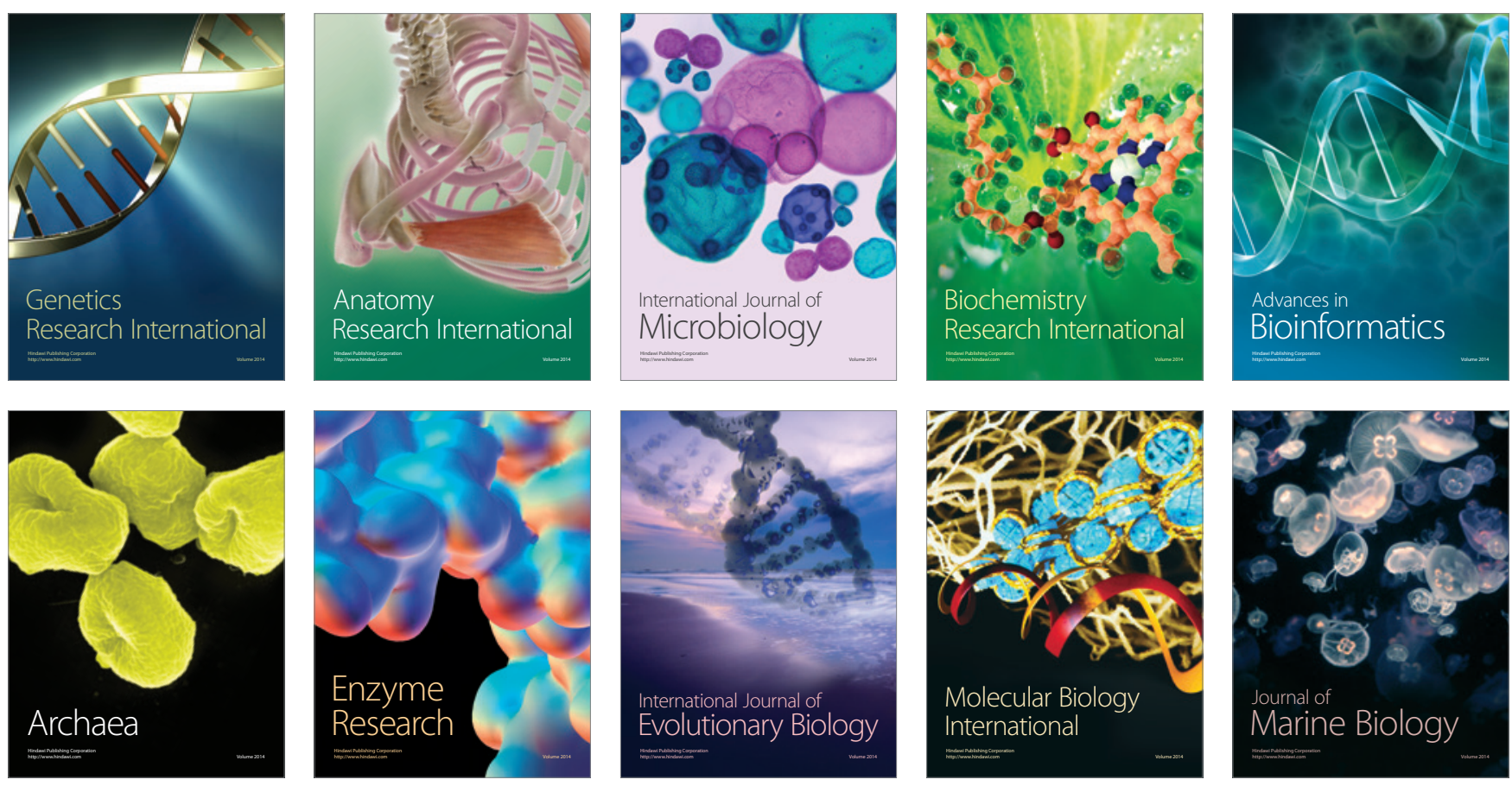